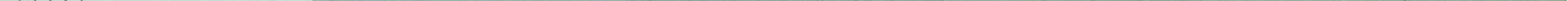




\section{DISCLAIMER}

This report was prepared as an account of work sponsored by an agency of the United States Government. Neither the United States Government nor any agency Thereof, nor any of their employees, makes any warranty, express or implied, or assumes any legal liability or responsibility for the accuracy, completeness, or usefulness of any information, apparatus, product, or process disclosed, or represents that its use would not infringe privately owned rights. Reference herein to any specific commercial product, process, or service by trade name, trademark, manufacturer, or otherwise does not necessarily constitute or imply its endorsement, recommendation, or favoring by the United States Government or any agency thereof. The views and opinions of authors expressed herein do not necessarily state or reflect those of the United States Government or any agency thereof. 


\section{DISCLAIMER}

Portions of this document may be illegible in electronic image products. Images are produced from the best available original document. 


\section{UNIVERSITY OF CALIFORNIA}

\section{Radiation Laboratory}

Berkeley, California

Contract No. W - 7405-eng -48

B EVATRON OPERATION AND DEVELOPMENT. XIII

February, March, April 1957

Walter Hartsough and William Salsig.

April 1, 1958

Printed for the U.S. Atomic Energy Commission 
This report was prepared as an account of Government sponsored work. Neither the United States, nor the Commission, nor any person acting on behalf of the Commission:

A. Makes any warranty or representation, express or implied, with respect to the accuracy, completeness, or usefulness of the information rontained in this report, or that the use of any information, apparatus, method, or process disclosed in this report may not infringe privately owned rights; or

B. Assumes any liabilities with respect to the use of, or for damages resulting from the use of any informaten, appers, method, or process disclosedinationt.

As usedin the oven, "person acting on behalf of the Commission inclufes any employee or contractor of the Commiss to the extent that such employee or contractor pterares, handires or distributes, or provides access to, any information pursuant to his employment or contract with the Combisstion

o.

Qtis 
BEVATRON OPERATION. AND DEVELOPMENT. XIII

\section{Contents.}

Abstract . . . . . . . . . . . . . . . . . . . . . 3

Magnet-Coil Shroud: Failure and Repair

Failure of the Magnet-Coil-Shroud Corner Retainers . . . . 4

Redesign and Replacement of the Shroud Corner Retainers . . . 6

Integration of Previously Scheduled Shutdown Work into the Shroud Reconstruction Job............. . . . . 14

Location and Elimination of Vacuum-Tank Electrical Shorts . : 14 Magnet Power Supply . . . . . . . . . . • • . . . . . 15

Modifications for New Experimental Areas and Improvements to . . . 16

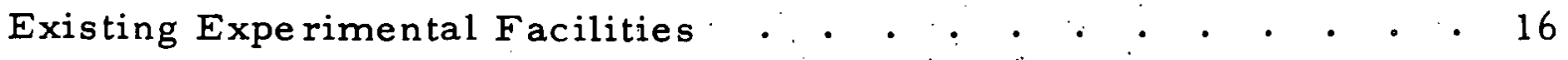

Creation of the North Experimental Area . . . . . . . . . 16

Improvement of Northwest (K Station) Experimental Area . . . 16

Start of an Experimental Area 28 3/4 Degrees into Quadrant III . 17

Improvement of the West Experimental Area . . . . . . . . 17

Four-Sector Stanchion . . . . . . . . . . . . . . . . . . 17

Three-Sector Stanchion. . . . . . . . . . . . . . 27

Magnet-Coil Box Resupport . . . . . . . . . • $\cdot{ }^{\circ} \cdot 31$

Experimental Facilities

Radiation Shielding.-Extension of the Shielding-Wall Foundation. 36

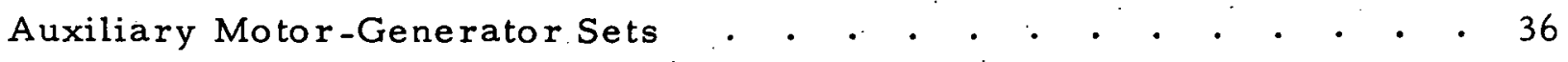

Pole-Base-Winding Field Correction . • . . . . . . . . . . 40

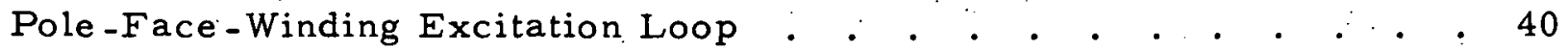

Development of MK VII Flip-Up Target . • • . • • . • . . . 40

Acknowledgments . 
BEVATRON OPERATION AND DEVELOPMENT. XIII

February, March, April 1957

Walter Hartsough and William Salsig

Radiation Laboratory

University of California

Berkeley, California

April 1, 1958

\begin{abstract}
During this entire quarter, the Bevatron was shut down for major rework of the magnet-coil air shroud and for the scheduled construction of a new experimental area at the north straight section. The existing west and northwest experimental areas were also improved. hauled.

The Bevatron motor-generator sets and associated ignitrons were over-
\end{abstract}

At the end of this period, the magnet coil rework is concluded and the scheduled shutdown work is well advanced. 


\title{
BEVATRON OPERATION AND DEVELOPMENT.XIII
}

\author{
February, March, April 1957 \\ Walter Hartsough and William Salsig \\ Radiation Laboratory \\ University of California \\ Berkeley, California
}

April 1, 1958

MAGNET-COIL SHROUD: FAILURE AND REPAIR

Failure of the Magnet-Coil-Shroud Corner Retainers

On January 31 , with each magnet pulse, a loud metallic noise was heard in the region of the Quadrant II outer-radius magnet coil. During each pulse the re was the sound of a sharp metallic impact, followed by the characteristic tinkle of falling sheet metal as the magnetic field decayed. Bevatron operation was suspended immediately and investigation was begun to determine the source of the noise. The magnet was single-pulsed while an effort was made to localize the noise in a single sector. The magnet was then disassembled in the region in which the sound was heard. An inspection of the magnet coil and vacuum tank (air side) regions in this area disclosed several mild steel coil-box corne $r$ retainers that had become free and had fallen into the space between the coil box and the vacuum-tank skin and were therefore free to move during magnet pulsing. In the oute $r$-radius space between the coil box and the vacuum tank, and in the three-sector area that was initially inspected, four angles were found loose with one or more rivets sheared; three were free and were found resting on the lower vacuum-tank corner bar. One of the free angles was found axially trapped behind a vertical vacuum tank rod; the upper end was badly mushroomed, indicating that with each magnet pulse it had risen vertically, loosely guided by the vacuum-tank rod, until it collided with the lower side of the vacuum-tank upper-corner bar. This piece was obviously responsible for the noise. An inspection of the corresponding space adjacent to the inner-radius coil indicated that the situation there was essentially the same.

Because these angle retainers were riveted together in pairs, one inside at the corners of the coil box sections and one outside, it was evident that for each angle that was found loose against the vacuum tank skin, one would also be loose in the masonite enclosure that forms the cooling-air shrouding around the magnet coils.

The Bevatron magnet is constructed in four quadrants. Each quadrant consists of 36 magnet sectors. The magnet-excitation windings are contained in four coil boxes within the magnet yoke and adjacent to the vacuum tank, as indicated in Fig. 1. To support the weight and to maintain the curved form of the windings, each of these coil boxes is divided azimuthally into. 72 sectors (two per magnet-yoke sector) by vertical stacks of molded bakelite coil-support forms. These forms, in addition to supporting and constraining the magnet coil, 


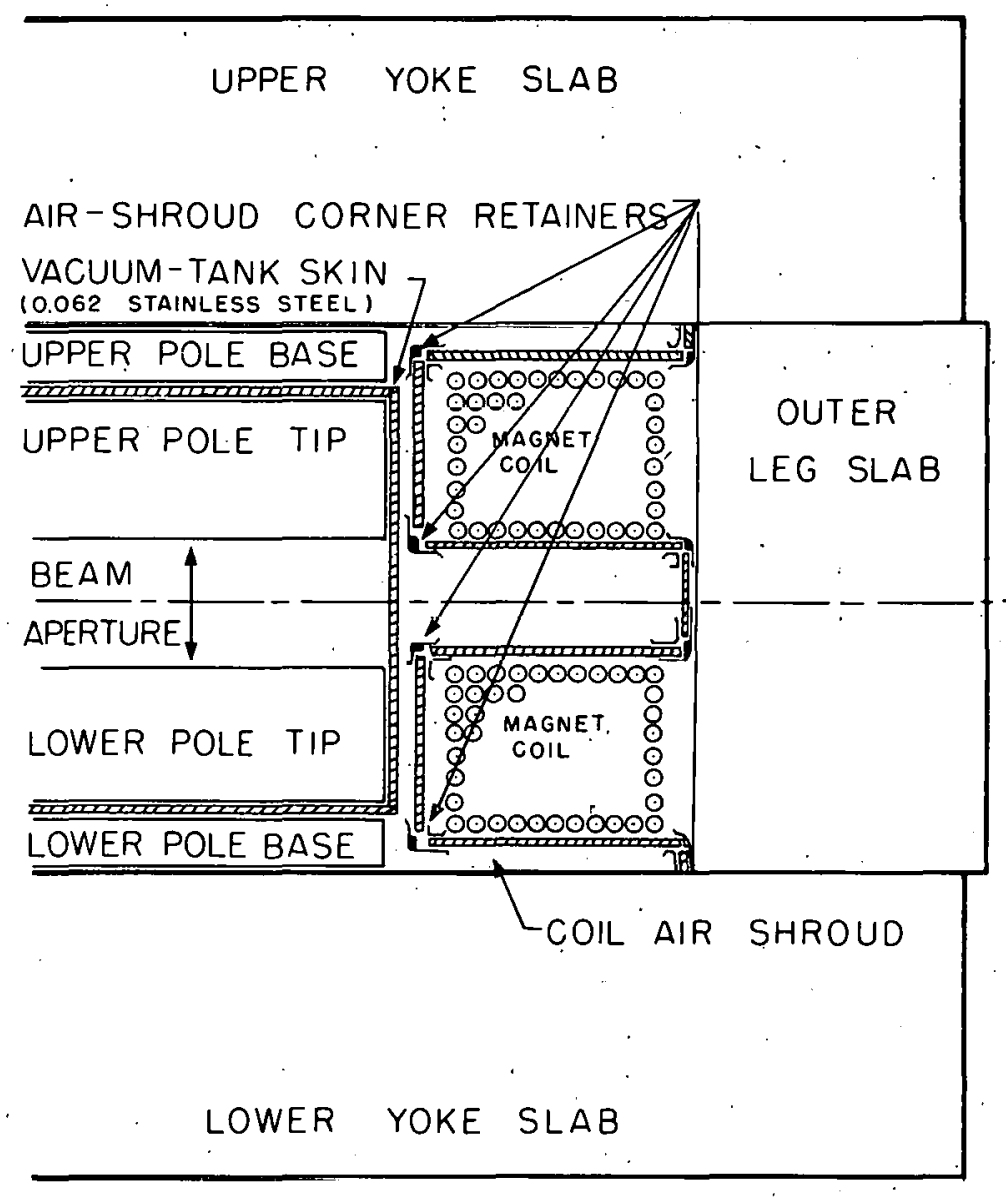

SIMPLIFIED CROSS-SECTION VIEW OF THE BEVATRON IN THE REGION OF' THE OUTERRADIUS COIL

MU-14209

Fig. 1. Simplified cross-section view of the Bevatron in the region of the outer-radius coil. 
constitute the radial partitions and baffles for the air-cooling circuit. Masonite panels tongue into grooves in the coil forms to make the tops and the bottoms of each sector of air shroud. The vertical shroud panels were held in position with respect to the top and bottom panels by 16 -gauge mild steel sheet-metal angles which were riveted to one of the masonite sheets in such a manner as to form a slip joint which retained the other masonite sheet. It was these steel angles which, because of repeated flexing in the magnetic field during pulsing, had in many cases sheared the rivets that bonded them to the shroud, and had become free.

Figure 2 shows the coil boxes during the original construction period before the vacuum tank was installed.

Evaluation of the failure in the three-sector area in which the noise was heard resulted in an estimate that probably at least as many as $20 \%$ of the more than 2,000 pairs of angle retainers were either loose or completely free. It was evident that the failure was not a local or isolated incident, but probably represented a condition that was uniform around the magnet. Each of the 4,000 angles was therefore a potential source of serious damage to the magnet windings or the vacuum-tank skin. For this reason, the decision was made to suspend Bevatron operation for whatever period of time would be necessary to accomplish a redesign and rebuilding of the magnet-coil boxes with nonmetallic corner retainers.

Subsequent experience confirmed the correctness of the original findings and assumptions. Approximately $25 \%$ of the coil air-shroud retainers nearest the pole tips were either loose or free, and this condition was rather uniform around the entire magnet.

\section{Redesign and Replacement of the Shroud Corner Retainers}

Although the decision to rebuild the coil boxes was made as soon as the nature of the failuce was determined, the actual disassembly and corrective work was delayed until an engineering evaluation of the job was made.

The original sequence of coil-box assembly precluded the disassembly of the air shroud without destroying the existing masonite pieces. In order to avoid a costly and time-consuming redesign and reconstruction and in orde $r$ to reutilize the original pieces of the air shroud, a nondestructive method of removing the corner retainers from the shrouding had to be devised. With the exception of the retainers at the top of the upper coil box, the retainers were not directly accessible (Fig. 1). Tools had to be designed and developed to operate in the confined spaces between the upper and lower coil boxes and between the coils and the vacuum tank without the danger of damaging either the vacuum-tank skin or the magnet windings.

Remotely operated tools were therefore built which allowed deriveting in place, and retrieving of the corner retainers. New bakelite retainers (Fig. 3) were made which could be installed without disassembly of the shroud and could be remotely handled during installation. Additional inspection and cleaning tools we re designed and built. 


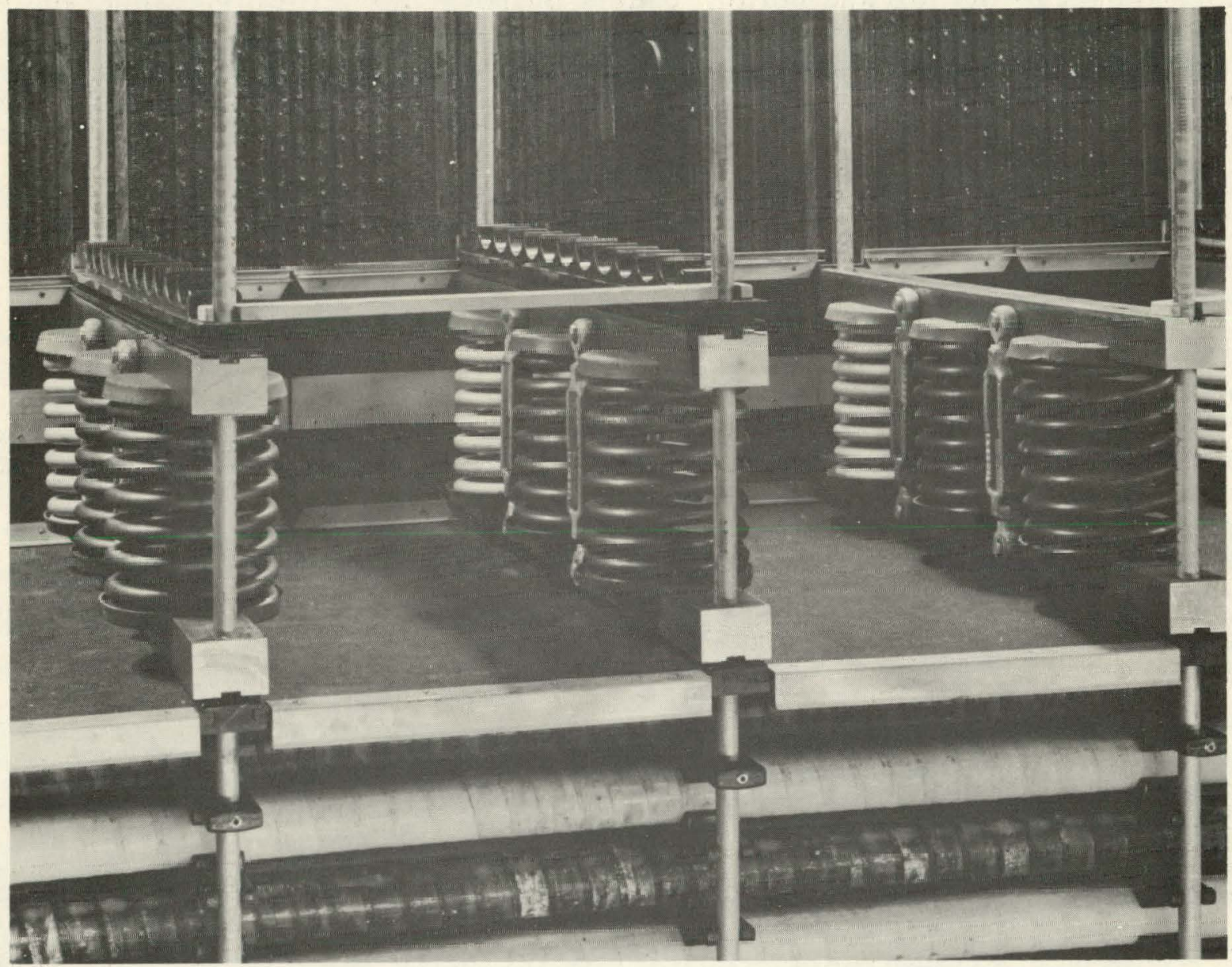

$\mathrm{ZN}-1900$

Fig. 2. Lower magnet coil, upper-coil spring supports, and upper-coil form during construction of the Bevatron. This picture was taken before the vacuum tank was installed and clearly shows the relationship of the coils, coil forms, coil boxes, and the coil-box corner retainers. 


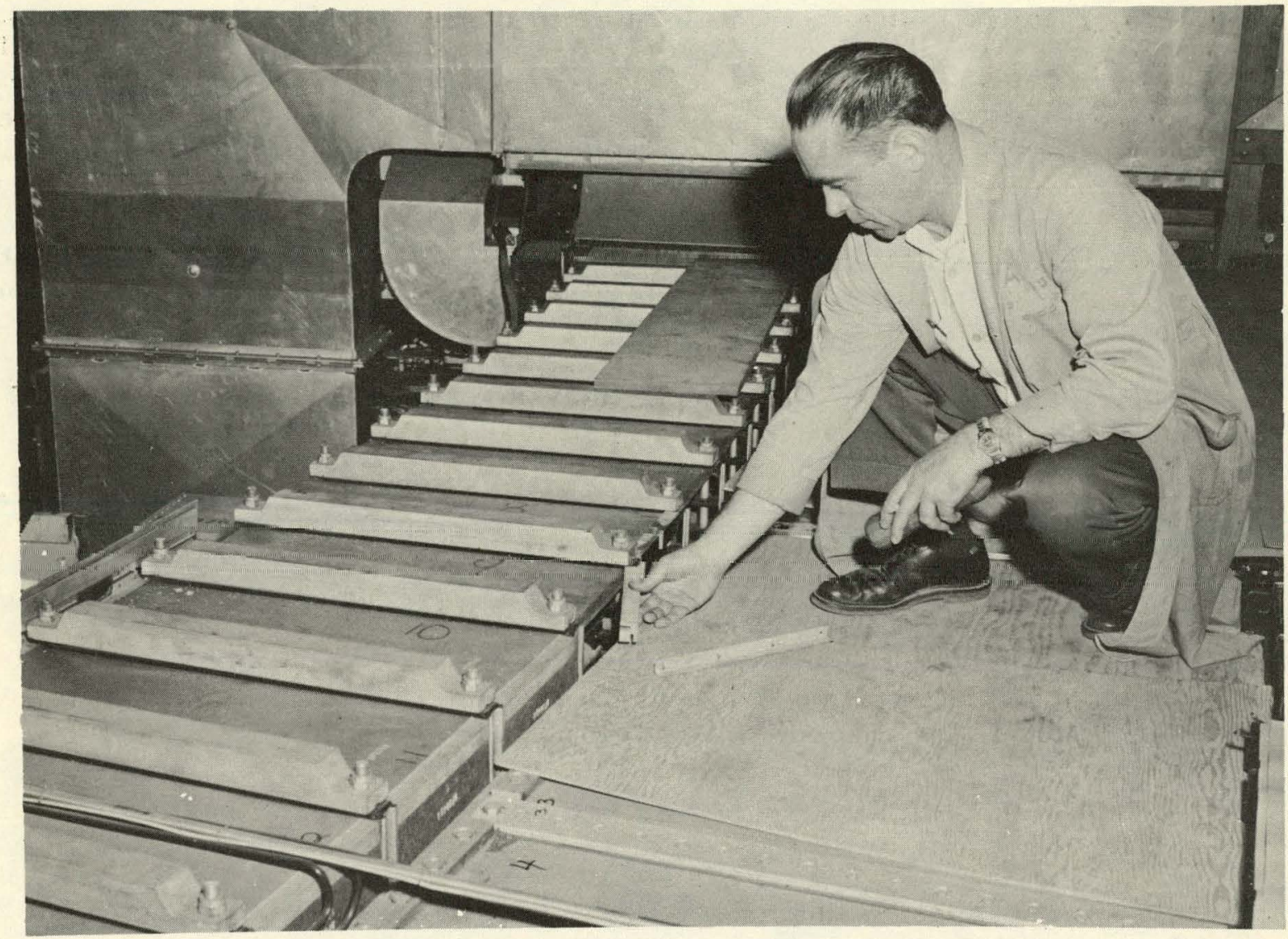

$\mathrm{ZN}-1901$

Fig. 3. Replacement of the coil-box mild steel retainers with bakelite retainers. 
The actual corrective rework began on February 7 . Because the coil forms are radially constrained by the inner and outer leg slabs, the danger of the coils' deforming existed if the magnet were disassembled in large sections. The corrective work was therefore carried on in regions of not more than seven magnet sectors in azimuth (Figs. 4 and 5). Generally speaking, work was done in two quadrants simultaneously. work:

The following jobs were integrated into the coil air-shroud reconstruction

1. A thorough inspection was made of the coil spaces and of the magnetwinding insulation by means of specially designed illuminated viewing prisms (Fig. 6).

2. All air-shroud pieces were checked for mechanical damage. Existing steel clips were retained on pieces farthest from pole tips, but the number of securing rivets was doubled and faulty existing rivets we re replaced.

3. The spaces between the vacuum tank and the magnet windings were inspected and cleaned.

4. Electrical shorts between sections of the vacuum tank were removed wherever possible.

5. All vacuum-tank pumpout circuits were vacuum-checked. Leaks were repaired where possible.

6. Additional insulation against electrical shorts was provided at the junctions of the vacuum-tank skin and vacuum-tank frame members.

7. Better mechanical support was provided for electrical leads to the upper pole-base winding in the regions of high magnetic field.

8. Styrofoam spacers under the lower coil boxes were replaced with fireretardant styrofoam.

9. The magnet-winding insulation was high-voltage checked.

Figure 7 shows the predicted and actual rates of completion of the coil-box rework. 


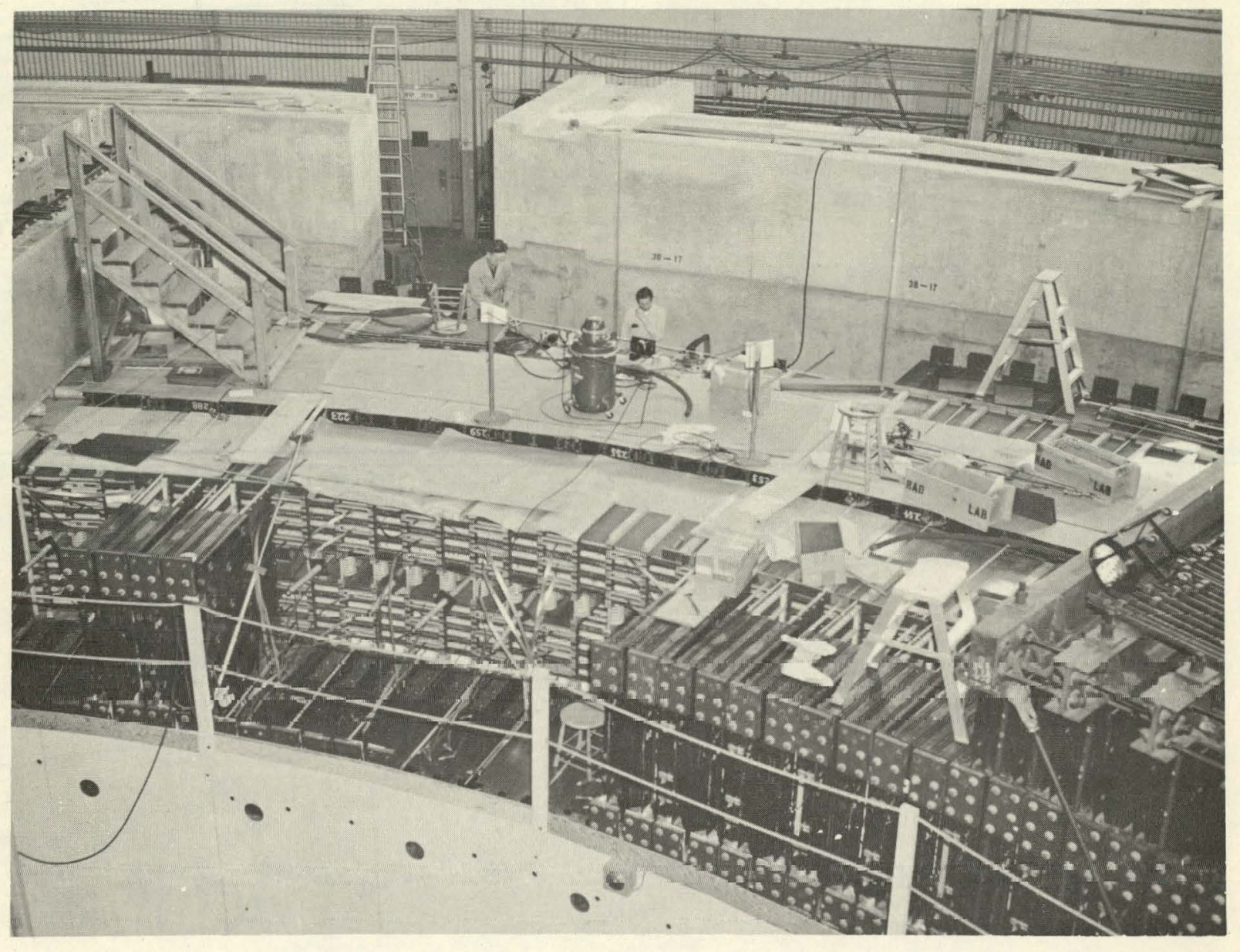

ZN-1902

Fig. 4. Rework of magnet-coil boxes. 


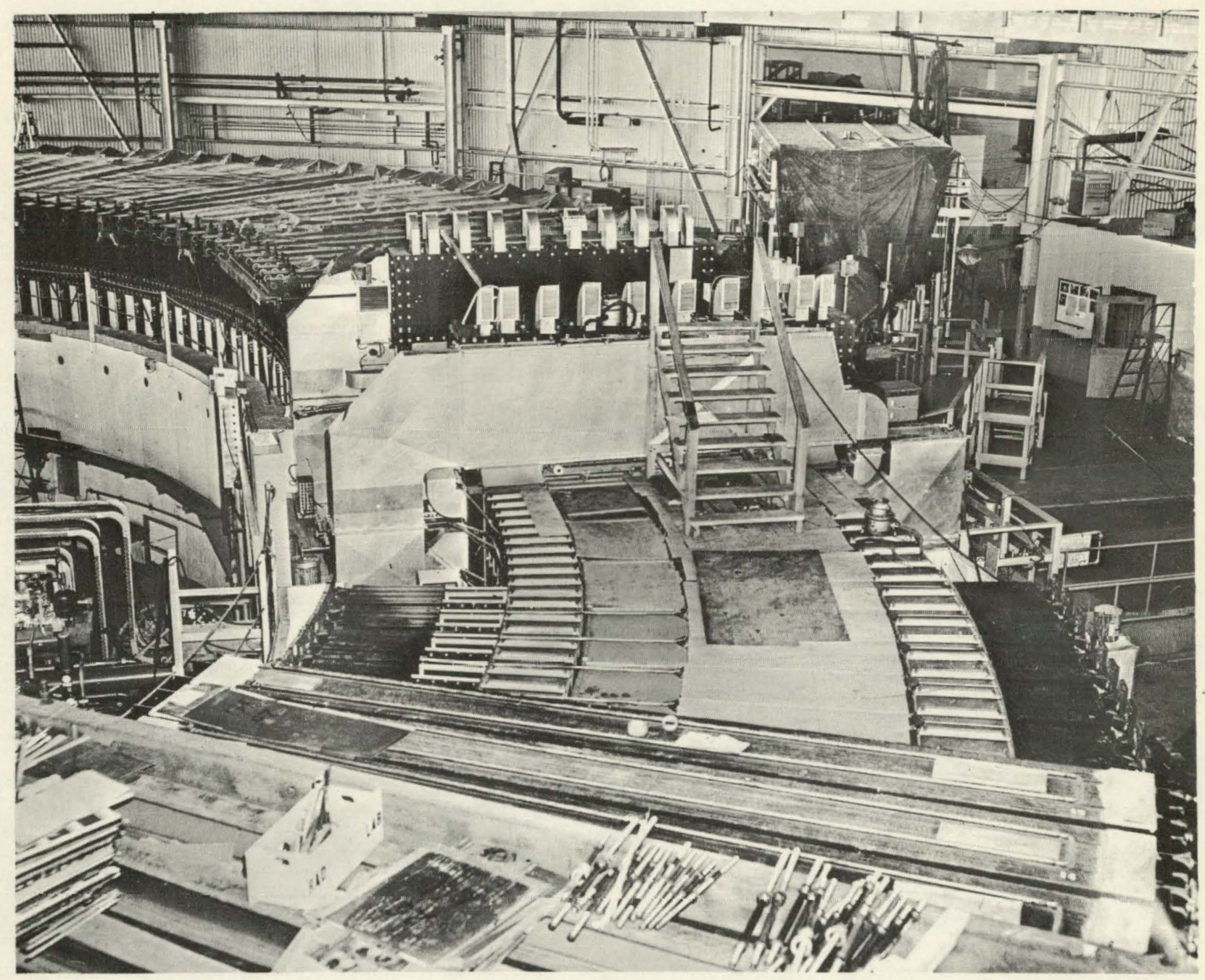

ZN-1903

Fig. 5. Rework of magnet-coil boxes. 


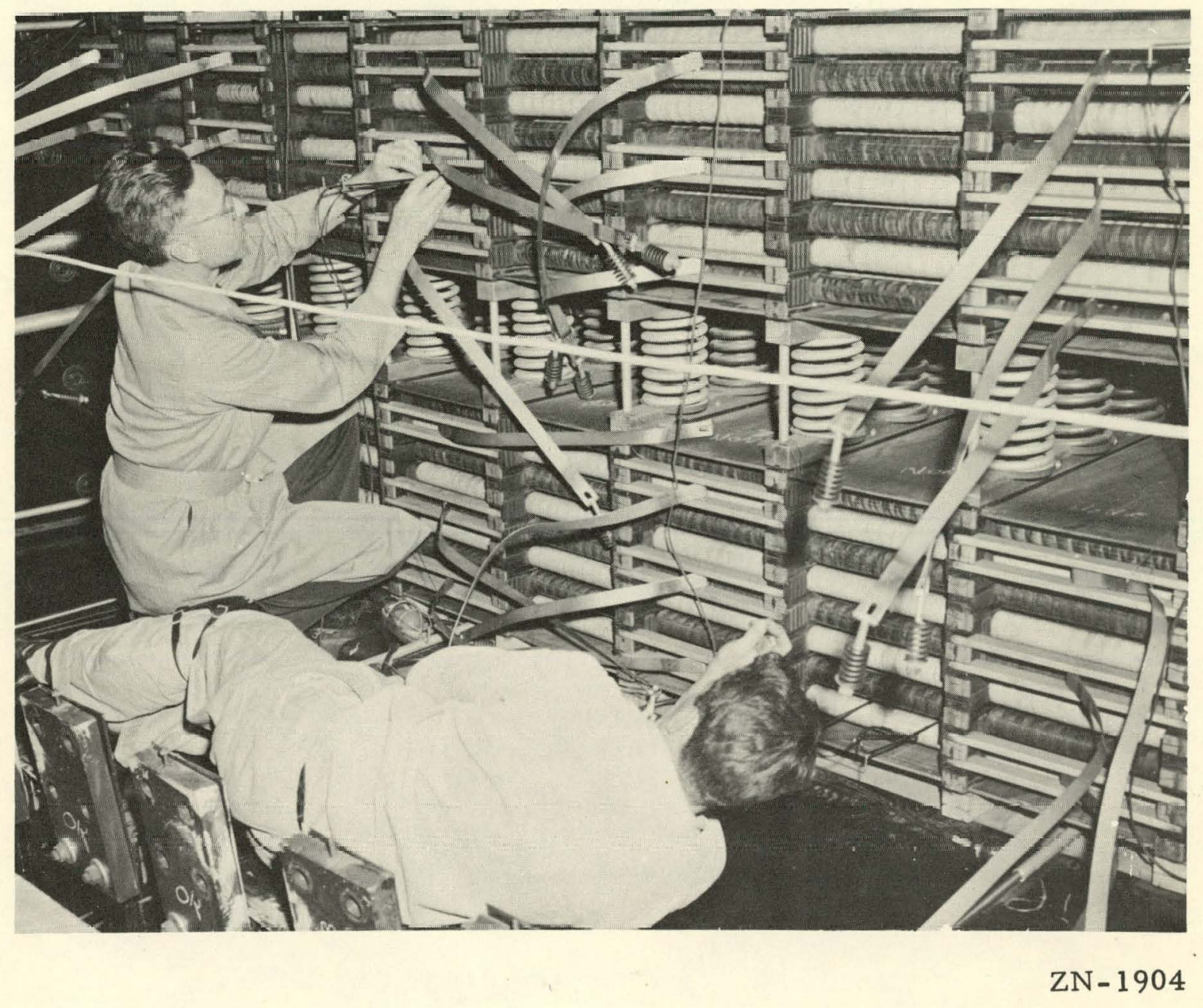

Fig. 6. Visual inspection of the magnet windings, using illuminated prisms. 


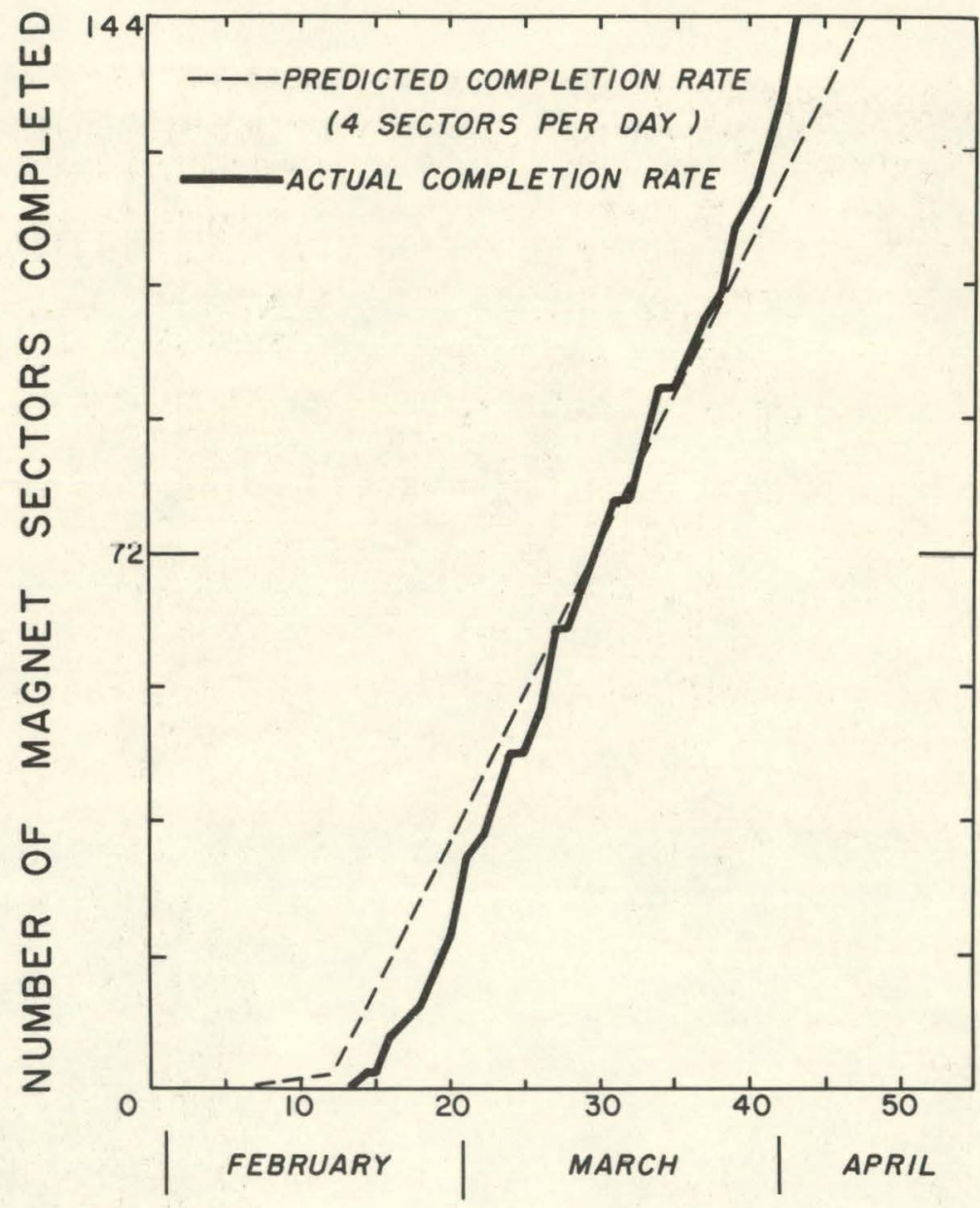

WORKING DAYS

MU-14905

Fig. 7. Rate of completion of Bevatron magnet coil rework. 
Integration of Previously Scheduled Shutdown Work into the Coil-Shroud Reconstruction Job

Because the estimated completion date of the coil-shroud reconstruction work approached the starting date of a major shutdown scheduled:for construction of an experimental area at the exit of Quadrant III, the decision was made to expedite the completion of parts for the scheduled shutdown and to integrate this shutdown work into the coil rework wherever possible. In this manner, time would be saved and duplication of effort could be avoided.

A description of the scheduled shutdown work appears in a later section of this report.

L ocation and Elimination of Vacuum-Tank Electrical Shorts

Since the beginning of Bevatron magnet pulsing, the re have been many occurrences of electrical shorts between adjacent sections of the vacuum tank. To insure against damage to the vacuum-tank skin due to large circulating eddy currents, protective circuitry monitored the resistance beitween tank sections and automatically interrupted magnet pulsing if the resistance became lower than a permissible value. A record was kept as the shorts appeared, and whenever a new short occurred or an existing short became mo re "solid," a careful evaluation was made of the risk of continued operation. Individually, the shorts did not constitute a serious hazard. However, the possibility existed that shorts between several adjacent sections could occur in such a fashion as to form a large electrical circuit, or loop, coupling a large number of lines of magnetic flux.

During the disassembly of the magnet for rework of the coil boxes, a careful investigation was made of the electrical shorts that existed between the vacuum tank frame and skin members and between the vacuum tank and adjacent magnet sections. It was immediately obvious that the majority of the shorts were due to the loose coil-box corner retainers that were free to be moved within the confines of the coil-box vacuum-tank space by the magnetic field. Many angles, probably after some period of wandering, had become wedged between the lower vacuum-tank skin and vertical vacuum-tank rods. In any case, many: of the angles we re found resting in such a position as to cause an electrical short between a section of the vacuum-tank skin and the tank frame. These shorts were all eliminated.

A relatively small number of shorts were detected that were not associated with the angles. Whe re possible, these shorts were isolated and cleared. Several that existed between top-skin sections and frame members at the vacuum-gasket joint were located and eliminated. In these shorts, sufficient heat had been generated to carbonize small volumes of the rubber gasket, although not enough to create a vacuum leak. It was, of course, not possible to correct this type of short between side or bottom skin sections and the frame members because of inaccessiblity. 


\section{MAGNET POWER SUPPLY}

During this shutdown period, thorough inspection and repair we re made of all the critical components of the magnet power supply. and, where necessary, units were rebuilt or replaced.

The following is a summary of the major jobs that were undertaken involving magnet power-supply equipment:

1. The generator stator windings of both generators were completely rewedged, with keepers that will eliminate the drift of the end wedges during generator operation. All the slot wedges were driven in place, butted one against the next, so that no axial motion is allowed as long as the end wedges are constrained.

2. The shafts of both gene rators were realigned.

3. New torsional twist indicators and alarms were installed on the generator shafts.

4. The generator journals and the shaft-coupling bolts were magnaflux inspected.

5. All ignitrons and ignitron systems were lead-checked. Nine ignitrons we re rebuilt (the graphite parts of four of the overhauled ignitrons we re vacuumoutgassed at $1650^{\circ} \mathrm{C}$ ) and degassed at high current.

6. The ignitron fault-monitoring system was improved by installation of automatic oscilloscope-came ra recording equipment.

7. New thyratron grid circuits were installed for tests in two ignitron circuits.

8. Minneapolis -Honeywell pneumatic temperature regulators were installed on all ignitron units to provide $0.5^{\circ} \mathrm{C}$ wate $\mathrm{r}$-temperature regulation on the ignitron barrels.

9. The lubricating-oil pump systems and oil-monitoring equipment for the motor-generator sets were overhauled; the gear pumps were replaced with centrifugal pumps.

10. The electrical insulation on both generator sets was high-voltage checked.

-11. A general overhaul was made on all operational, protective, and monitoring equipment associated with the generator sets. 
MODIFICATIONS FOR NEW EXPERIMENTAL AREAS AND IMPROVEMENTS TO EXISTTNG EXPERIMENTAL FACILITIES

Prior to the forced shutdown for coil air-shroud repair, a long-term program including several major changes to increase the experimental effectiveness of the Bevatron had been maturing. A 5 - to 6 -week shutdown would be required to effect these changes', and fabrication was already under way for a scheduled starting date towards the middle of April. The changes envisioned and subsequently included during this shutdown we re:

\section{"Creation of the North Experimental Area'}

1. Provide a four-sector stanchion and beam aperture at the outer-radius exit of Quadrant III, including cooling system for stanchion and magnetic-fieldcorrection coil.

2. Resupport of the magnet coil opposite the four-sector stanchion in order to allow removal of the support springs which would have been obstructions to the secondary-particle beam, and provide a table over the lower coil to support shielding and beam collimation.

3. Provide a new leg slab at the outer-radius exit of Quadrant III with a slot to clear secondary-particle beams.

4. Resupport the outer-radius end of the upper and lower coil boxes to allow removal of vertical support posts which would have otherwise obstructed the secondary-particle beams.

5. Provide a heavy-duty $\left(2000 \mathrm{lbs} / \mathrm{ft}^{2}\right)$ platform (to replace the then existing $60 \mathrm{lb} / \mathrm{ft}^{2}$ platform) at the outer radius of the north straight section. In addition, replace the high-level platform above this area with a new drop-leaf structure to allow crane access to the main deck. A further required addition was a balcony under the main platform to allow direct access to auxiliary magnet power connections in this area.

6. Provide filtered and monitored water distribution of 180 -gpm capacity, with four services to north area, one to northwest (K station) area, and two outlets in a trench outside the north shielding wall for service of auxiliary equipment.

7. Provide a new shielding wall (similar to west experimental a rea) with a 2 -foot slot at beam level across north experimental area.

\section{Improvement of Northwest (K Station) Experimental Area}

1. Rework the outer-radius one-sector stanchion, removing a vertical rib and maintaining the original strength with a picture-frame insert, thus doubling the particle-acceptance aperture at the vacuum-tank wall. 
2. Install a bellows-articulated vacuum tube from the vacuum-tank wall, terminating in a 0.010 -inch-thick aluminum window just outside the magnet leg slab (Fig. 8). Particles are thus retained in vacuum 5 feet further than before, and the 0.062 -inch stainless vacuum-tank wall beam obstruction was replaced with 0.010 inch of aluminum.

3. Improve the radiation shielding opposite this area.

Start of an Experimental Area 28.75 Degrees into Quadrant III

1. Install a three-sector stanchion at the outer radius of Sectors 83,84 , and 85 .

2. Provide an air-cooling system for this three-sector stanchion. This experimental area will be completed in 1958 with the primary purpose of providing Bevatron beams to the 72 -inch liquid hydrogen bubble chamber in the Bubble Chamber Building.

Improvement of the West Experimental Area

1. Resupport the outer-radius ends of the upper and lower coil boxes at the exit of Quadrant II to allow the removal of the vertical support posts, which would have otherwise obstructed secondary-particle beams from the twosector stanchion.

2. Resupport the magnet coil opposite the two-sector stanchion at the outer-radius exit of Quadrant II to allow removal of the intercoil support springs and provide a table over the magnet coil box to support collimation or shielding.

3. Provide a new heavy-duty wing platform at the north end of the west tangent tank outer-radius platform.

\section{Four-Sector Stanchion}

As initially conceived, the four-sector stanchion was to provide the same type of experimental facility at the exit of Quadrant III as had originally been provided at the exit of Quadrant II. Such a facility would relieve the congestion of experimental equipment then prevailing at the west area, and allow a greater number simultaneous experiments to be conducted at the Bevatron. Preliminary studies indicated that considerable advantage would result if an aperture more than two sectors long were incorporated in the new area. In particular, a single target serving the northwest ( $\mathrm{K}$ station) area would also give beam out of this new aperture, if it were sufficiently long, thus accommodating two experiments from a single target.

Design of this structure was not possible until valid load criteria were available. The original. Bevatron design bypassed this problem, as it was possible to provide structure capable of resisting the total magnetic force between pole tips, $150,000 \mathrm{lbs} / \mathrm{sector}$, assuming no support contribution from 


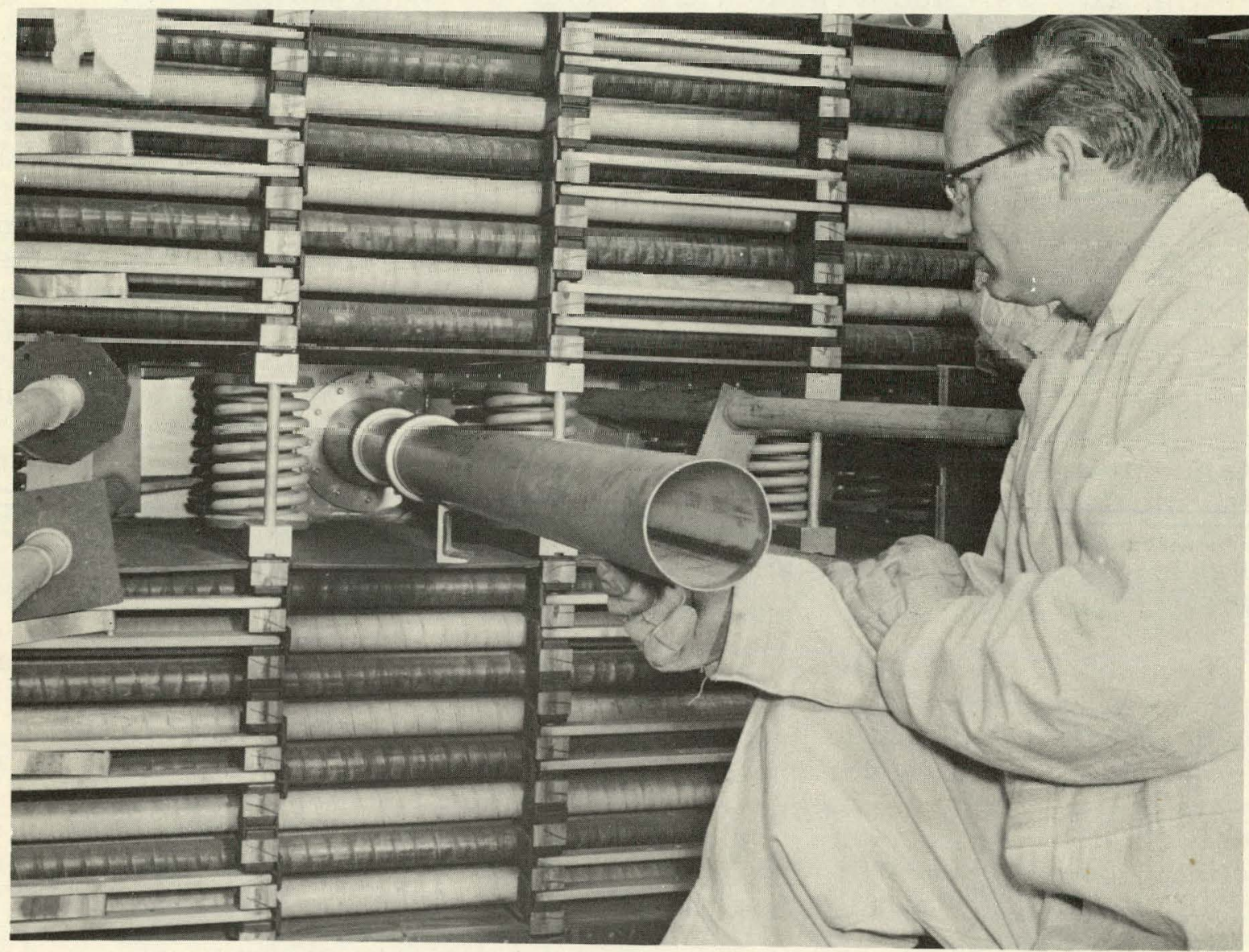

ZN-1905

Fig. 8. Vacuum tube at the northwest beam-exit location during installation. 
the magnet yoke. ${ }^{1}$ From practice, one knows that the yokes, by means of "magnetic glue," would probably support $1 / 2$ to $2 / 3$ of this pole-tip load. Preliminary studies indicated it was quite impossible to provide, in the space available, a structure that could carry the full pole-tip magnetic loads over the span desired, but if $2 / 3$ of the load were actually carried by the magnet yoke, feasible structures could be devised. Theoretical investigation of the magnetic load division indicated that the $2 / 3$ yoke support was probable, but the in determinates were too large to allow use of this approach as the sole design criterion.

Efforts were then made to evaluate the actual loads by the use of straingage techniques. Simultaneously, and for the same general reasons, strain gages were being used to evaluate the loads in the coil-box stanchions. The first impediment encountered was that the strain gages were profoundly affected in the pulsed magnetic field. ${ }^{2}$ After this difficulty was resolved, it became apparent that the magnetic load supported by the yoke was a function of the deflection of the supporting stanchion-the greater the stanchion deflection, the greater the yoke-support contribution. This situation arises because there was ample "magnetic glue" between the pole tip and yoke, but being elastic, the yoke must deflect to carry load. In the ultimate, one would have to provide a structure as elaborate as the intended stanchion to fully pre evaluate the stanchion loads. Fortunately, even with fairly stiff monitoring stanchions $(0.002$ inch total deflection, where 0.025 inch was permissible according to field-perturbation criteria), the yokes supported $2 / 3$ of pole-tip total loads, therefore the stanchion design and fabrication could proceed.

Procurement of this component posed many problems. Size and configuration placed the fabrication beyond UCRL machine shop capacity. Four months were required to find a vendor (to 26 requests for bids, only two vendors responded) and to process the order through the Atomic Energy Commission. The vendor made the steel (a modified type 316 stainless steel) in his own electric furnaces, as well as doing the forging and machining. The vendor's delivery schedule was disrupted by a strike, postponing the intended delivery date by 6 weeks, which raised serious doubt whether the part would be available for installation during the overhaul shutdown.

\footnotetext{
Total load per sector would have a possible maximum value on the order of $360,000 \mathrm{lb}: 150,000 \mathrm{lb}$ from magnetic loads, 24,000 from vacuum loads, 55,000 from yoke and pole-tip dead-weight loads, and 120,000 from yokeclamping loads. Properly monitored, yoke-clamping loads we re safely re duced to $20,000 \mathrm{lb}$.

2 Jack Gunn, "Magnetic Fields Can Affect Strain Gages," Control Engineering, August, 1957 -a report arising from this work.
} 
Re-evaluation of eddy currents that would be generated in the stanchion by the changing magnetic field raised a final problem. Experience arising subsequent to the original design indicated that an alternate eddy-current path was possible, enclosing considerably more magnetic flux than originally expected. Field perturbation and heat generation within the stanchion would be beyond acceptable limits. To accommodate this changed factor, the stanchion width was reduced from 6 to 4.5 inches, and a post was provided in the gap to compensate the reduced mechanical strength. The position of this post was determined by strain-gage monitoring of maximum stresses when the stanchion was proof-tested in the U. C. Structural Engineering Materials Laboratory testing machine (Fig. 9). Actually, very little aperture was lost, as proper post position was found to be within 15 inches of the end of the 75 -inch-long slot. However, three additional weeks were added to the fabrication time in order to execute these changes.

Eddy-current heat generation within the stanchion, originally estimated as on the order of 800 watts, and revised to possibly 2200 watts with the eddycurrent re-evaluations, required provision for abstracting this heat. If water cooling were to be used inside the Bevatron vacuum tank, a very serious hazard would result. A major water leak would cause an accumulation of water at the base of the lower pole tips in a space inaccessible to cleanup operations. Attempts to remove the water by vacuum evaporation would cause the water to freeze, and possibly many weeks of pumpdown-warmup cycles would be required to dry the vacuum tank. Attempts to warm the tank to speed evaporation at atmospheric pressure would possibly deteriorate the vacuum-tank gaskets. For these reasons, it was decided to cool the stanchion with compressed air or liquid freon (which, in the event of a leak into the vacuum tank, would evaporate). Since the available compressed air supply was adequate, this method was chosen.

Figures 10 and 11 show the four-sector stanchion complete with eddycurrent correction coil, air-cooling manifolds, and insulating spacer strips, ready for installation. Figure 12 shows the stanchion as installed. The air cooling manifold connections inside the vacuum tank are depicted in Figs. 12 and 13; the external distribution and monitoring manifold for the air cooling of both three-and four-sector stanchions is shown in Fig. 14. 


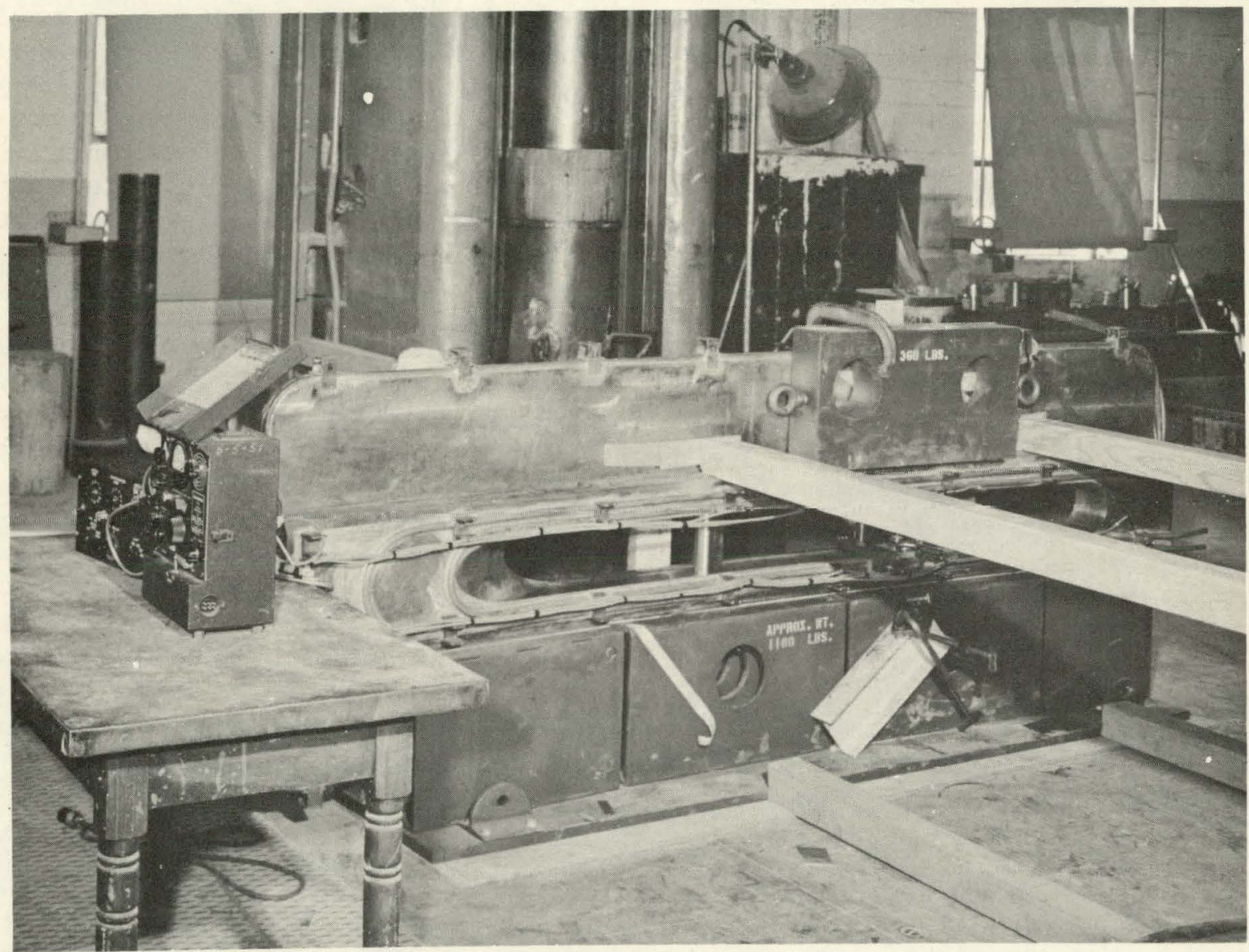

ZN-1906

Fig. 9. Four-sector stanchion during proof-test in the U. C. Structural Engineering Lab. materials testing machine. 


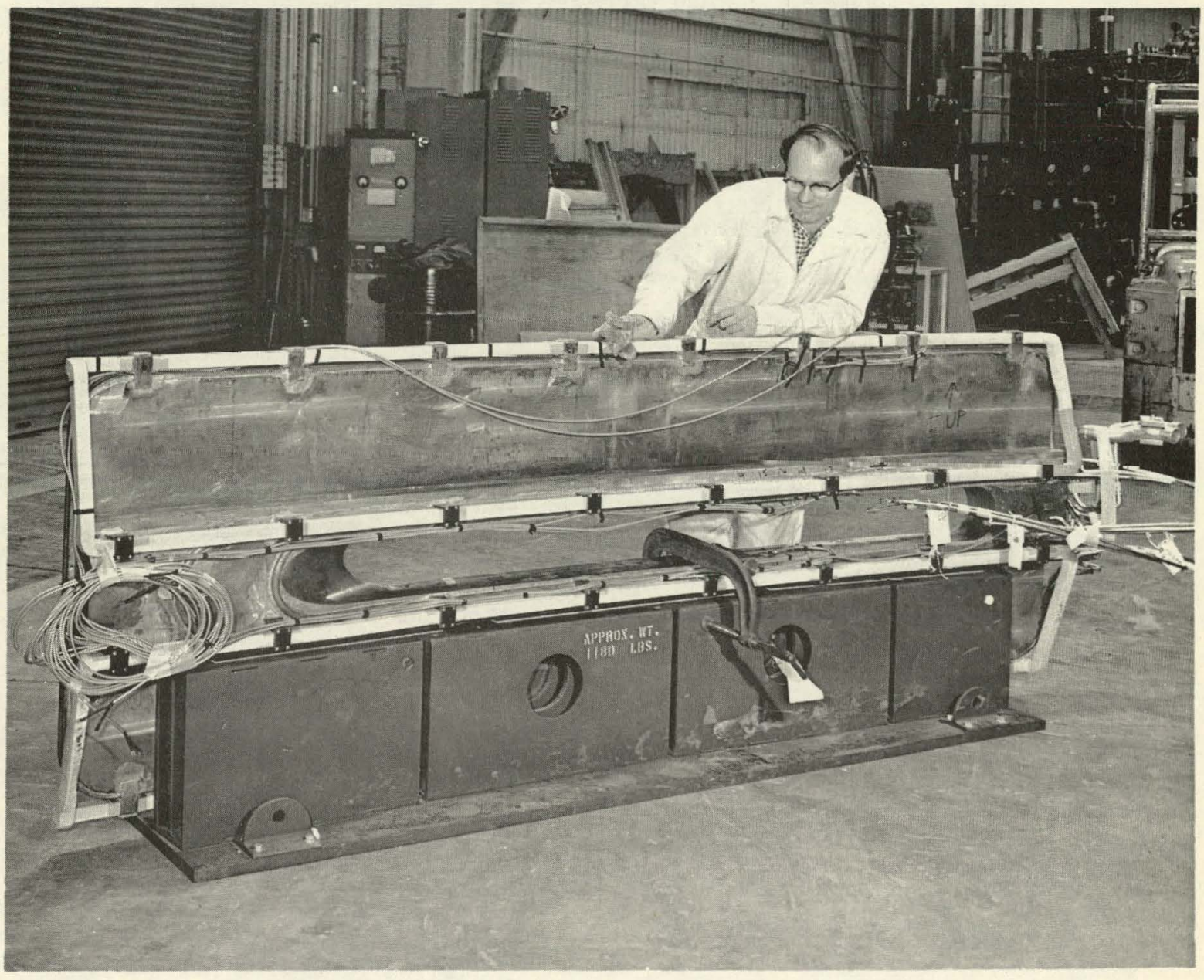

Fig. 10. Four-sector stanchion with air-cooling manifold and magnetic field correction coil. Inner surface. 


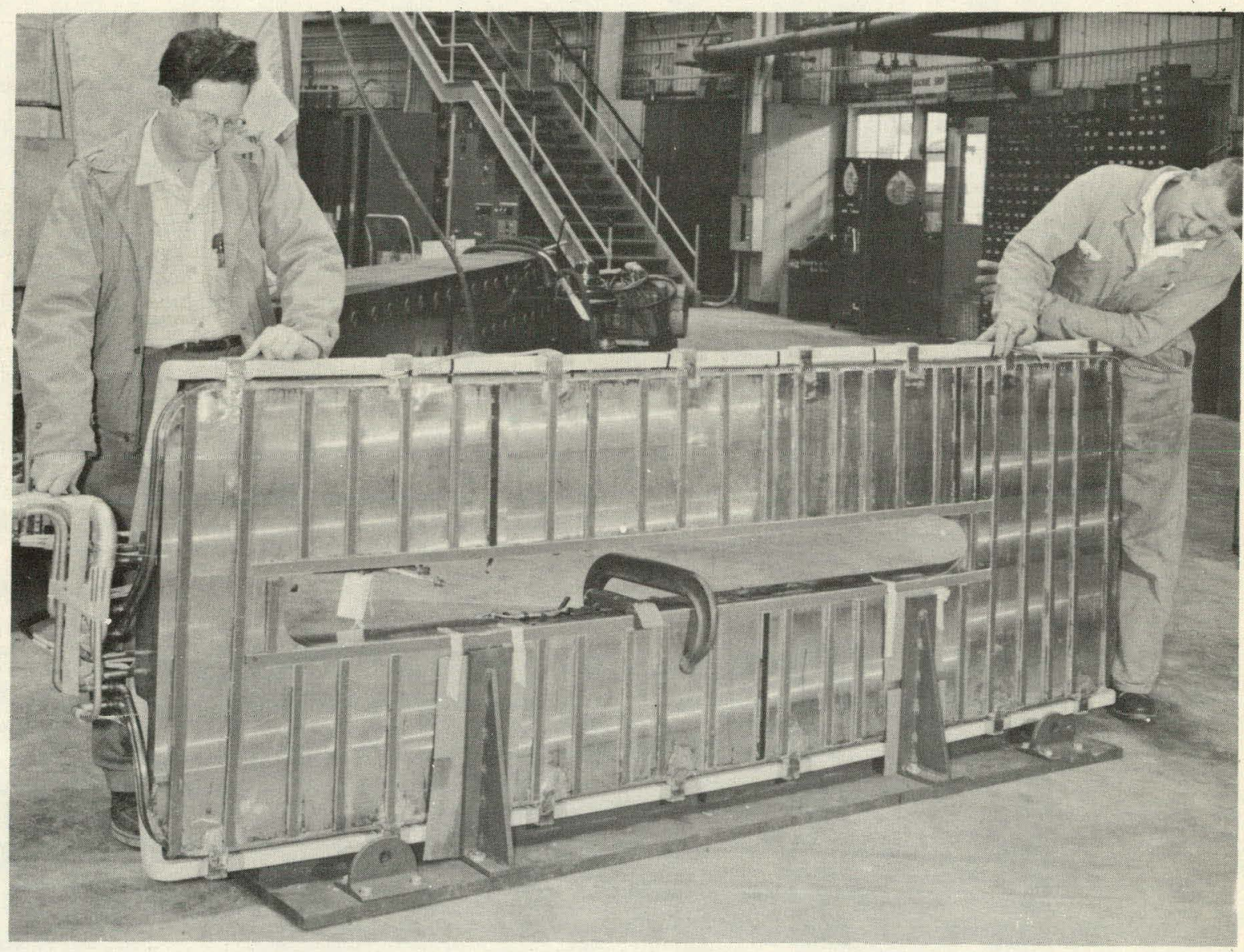

ZN-1908

Fig. 11. Four-sector stanchion with air-cooling maniford and magnetic field correction coil. Outer surface. 


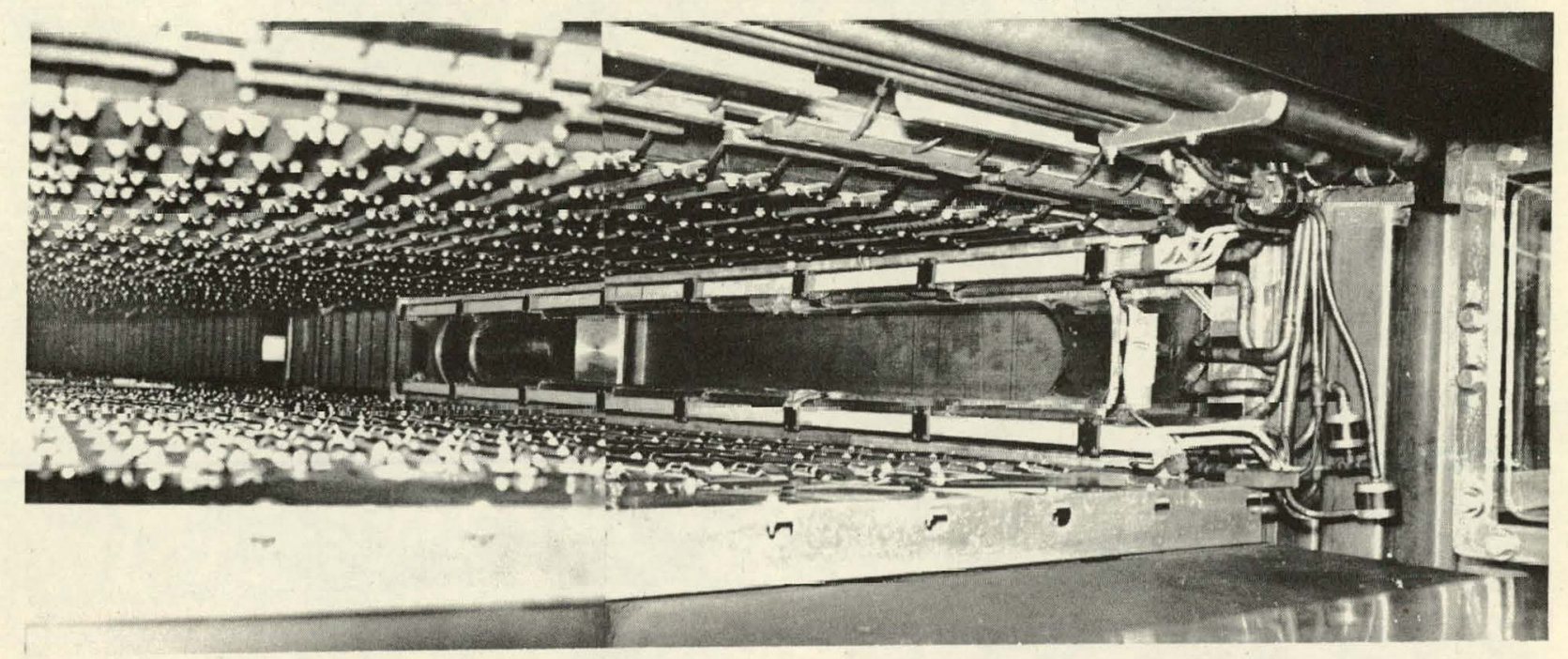

ZN-1909

Fig. 12. Four-sector stanchion installed at the exit end of quadrant III. The one-sector stanchion for the northwest experimental area ( $\mathrm{K}$-meson beams) can be seen toward the left side of the photograph. 


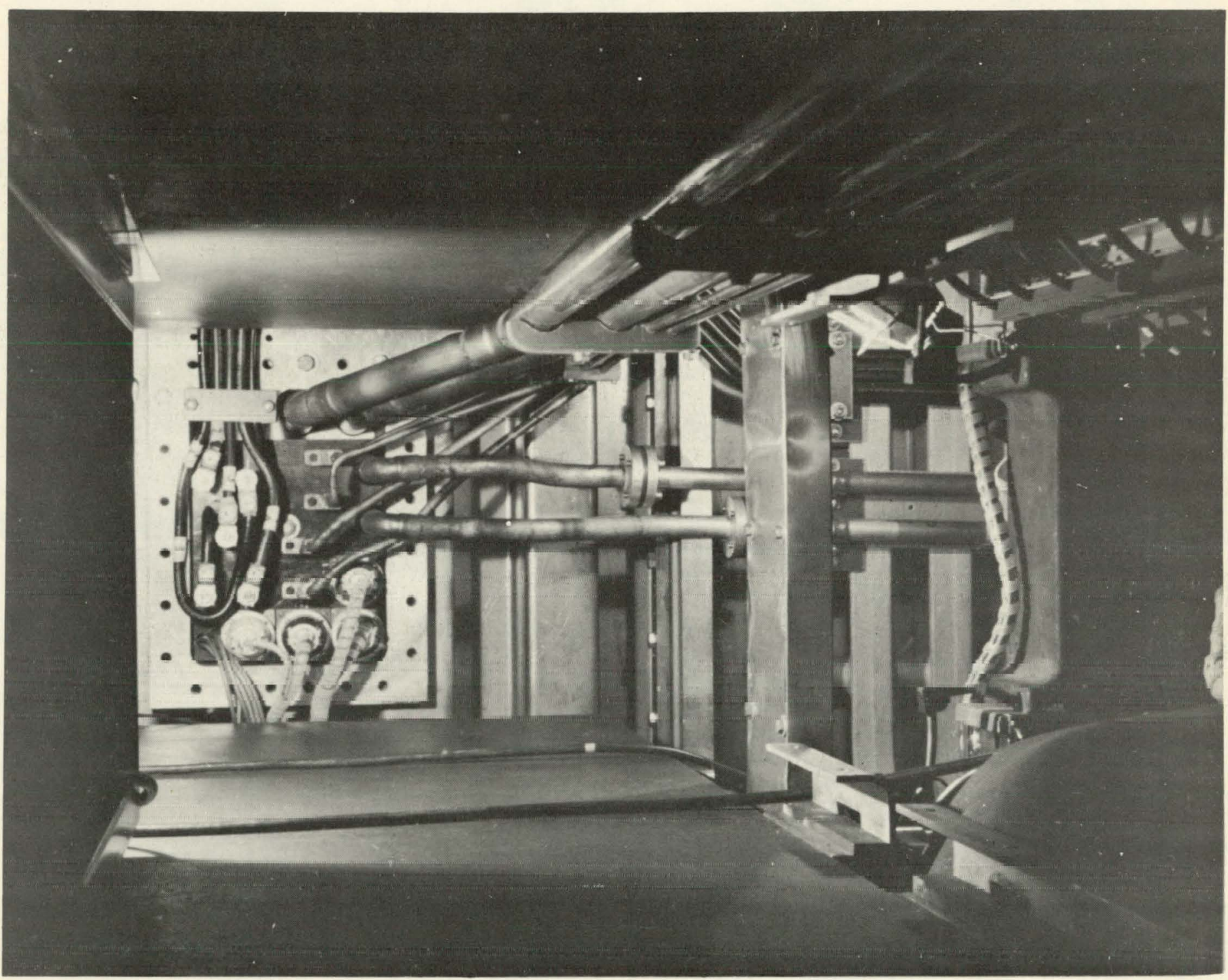

ZN-1910.

Fig. 13. Stanchion air-cooling and monitoring lines at the vacuum side of the vacuum feed-through plate. 


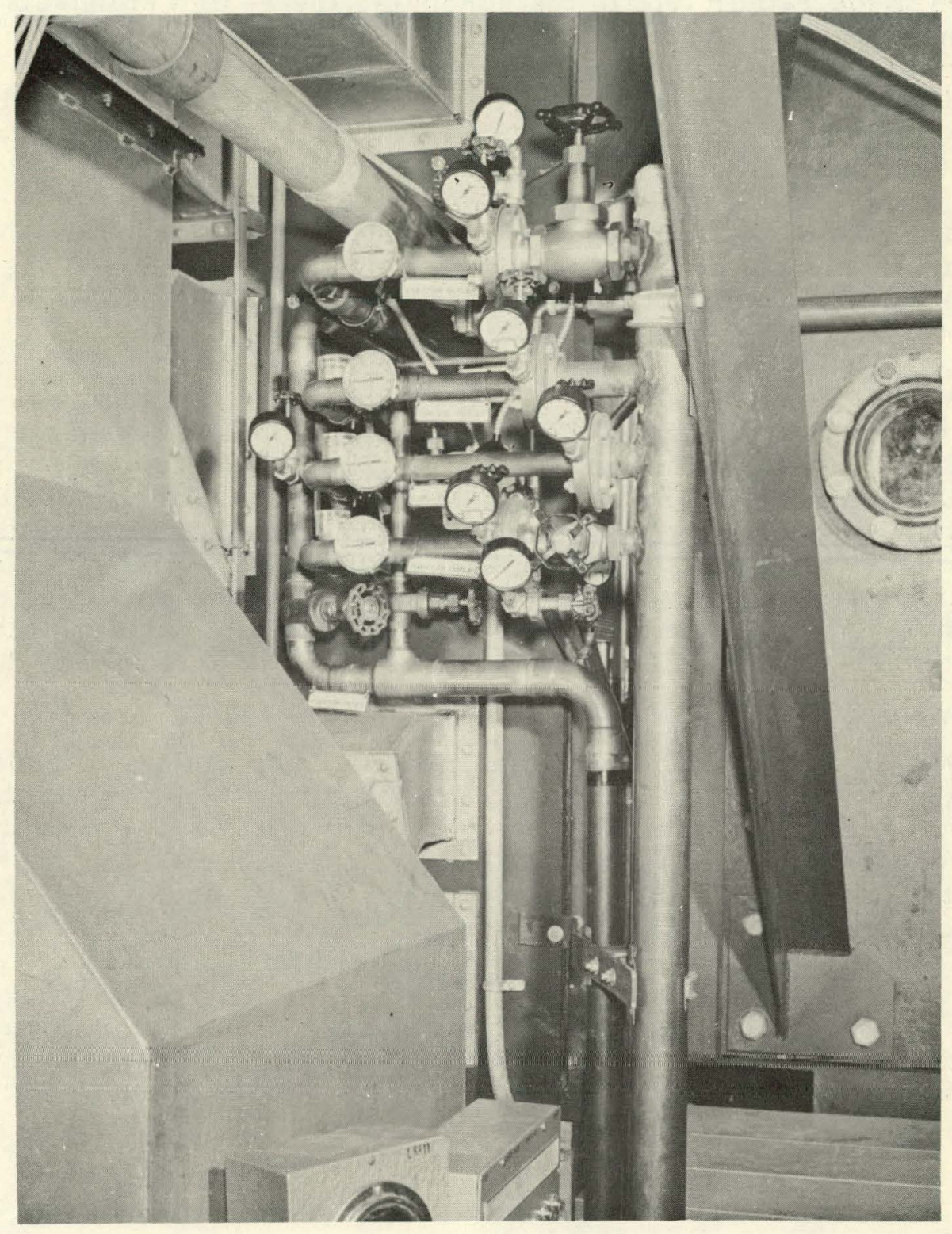

ZN-1911

Fig. 14. Distribution and monitoring manifold for the threeand four-sector stanchion air-cooling lines. 


\section{Three-Sector Stanchion}

After the painstaking load evaluation and structure studies required to engineer the four-sector stanchion, the three-sector stanchion, with only 47 inches of aperture length rather than the 75 inches for the four-sector unit, was a routine engineering job. Since the decision to incorporate this unit was made rather late in the schedule, the design emphasis was placed on using materials at hand ( 1 -inch and 1.5 -inch stainles steel plate) in a manner allowing local fabrication. The design evolved used a 1.5 -inchthick plate as the pole-tip support, which was multiply doweled to a 1 -inchthick wing plate. Although the structure was welded for fabrication facility, only the dowels are considered as load-transfer members.

Because of the minimum width, eddy-current generation was not considered sufficiently large to require a "buck out" or correcting coil, as provided on the four-section unit. However, copper manifolds for compressedair heat abstraction of the 800 -watt load were necessary.

As was done with the four-sector unit, the stanchion was instrumented with strain gages, and known loads and deflections were compared with train gage stress indications during proof-testing on the 3,000,000-1b test machine of the U.C. Structural Engineering Materials Laboratory. In this manner, one is able to calibrate the structure so that, when it is installed in the Bevatron, it is possible to evaluate the actual dead weight, clamping, and magnetic and vacuum loads as they are applied, and thus confirm the design adequacy. The sensitivity of this approach is remarkable. Although concentrated loads of $150,000 \mathrm{lb}$ were applied and measured, during the proof tests it was quite possible to detect the weight of a $150-1 \mathrm{~b}$ man at the midspan.

Monitoring data, during installation and during an extended period of Bevatron operation thereafter, indicate that the stress in the three-sector stanchion does not exceed 16,000 psi and in the four-sector stanchion it does not exceed 13,000 psi, while the original two-sector stanchion installed at the exit of Quadrant II showed maximum stresses above 24,000 psi with a satisfactory 5,000,000-cycle stress experience. One can say with conviction that no additional structural hazard has been introduced into the machine.

Figures 15 and 16 depict the three-sector stanchion, complete with cooling manifold and spacer insulation, ready for installation. Figure 17 shows the stanchion installed. 


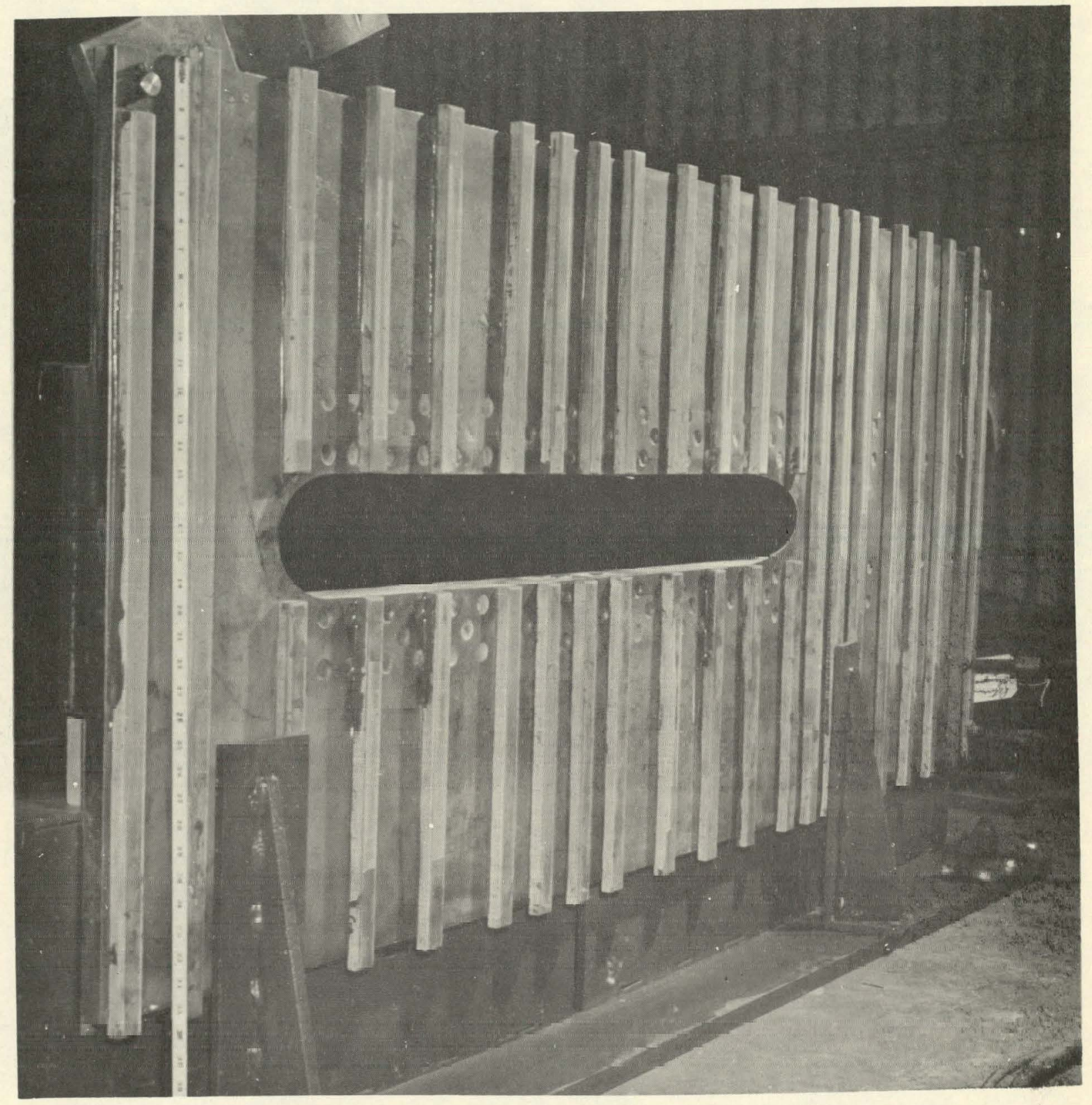

ZN-1912

Fig. 15. Three-sector stanchion ready for installation. Outer surface. 


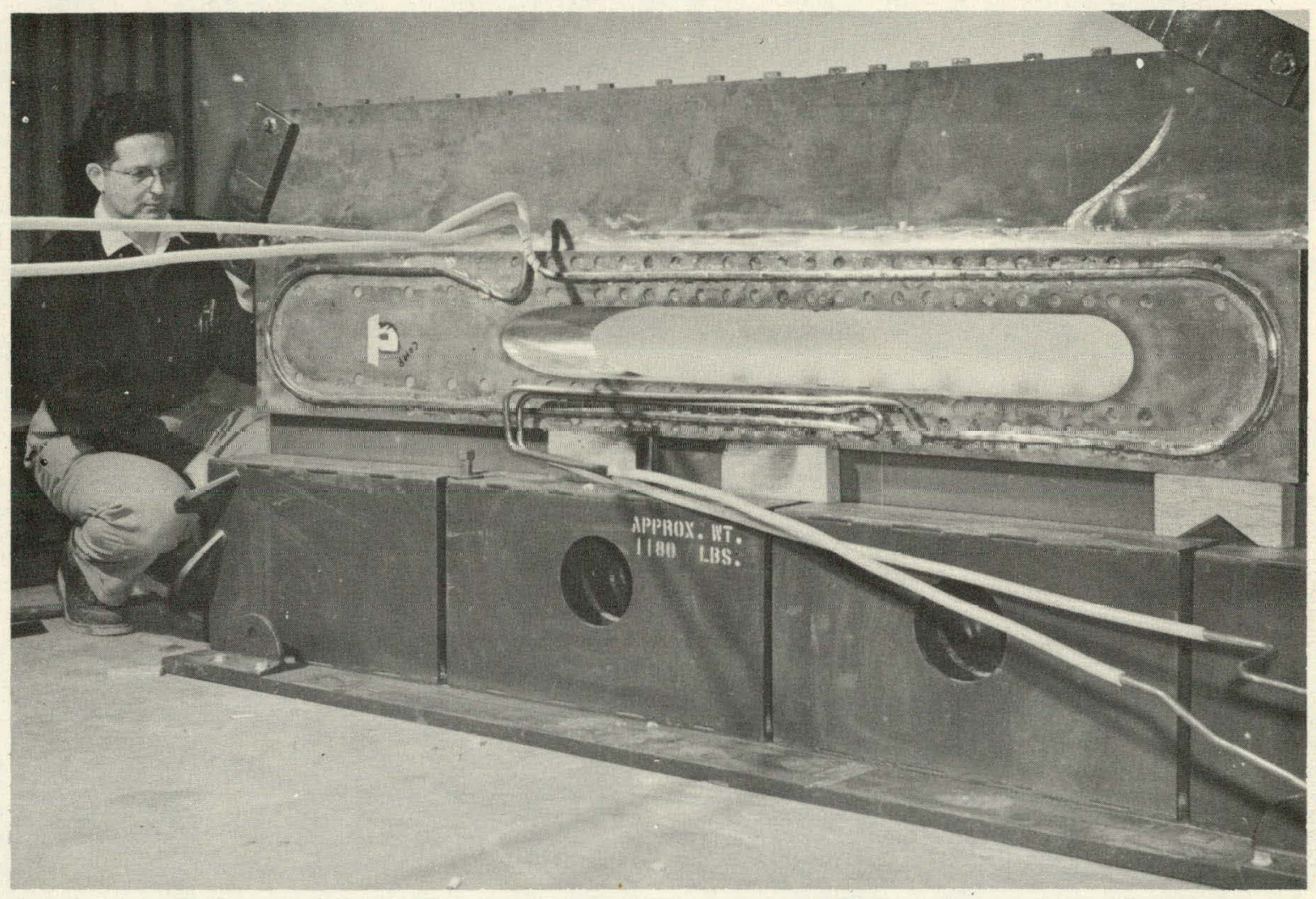

$\mathrm{ZN}=1913$

Fig. 16. Three-sector stanchion ready for installation. Inner surface. 


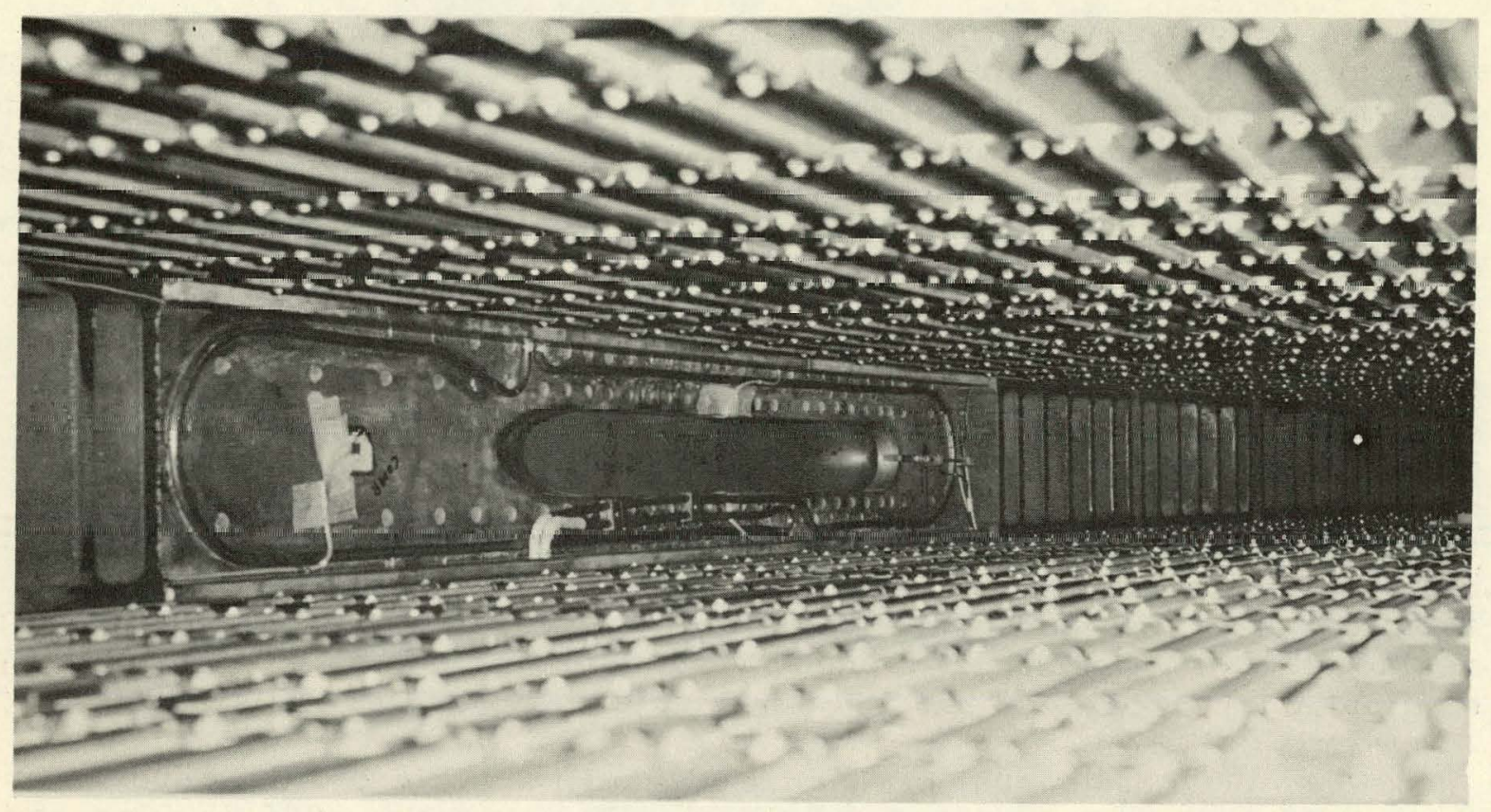

ZN-1914

Fig. 17. Three-sector stanchion installed in the Bevatron. 


\section{Magnet-Coil Box Resupport}

The original coil -box stanchions incorporated in the Bevatron posed the same load evaluation problems as the pole tip stanchions. Again, it was possible to provide structure strengths considerably in excess of actual requirements, which allowed by-passing precise load evaulations - an economic clesign approach. The original design proceeded from flux plot determination of conductor-magnetic field interaction loads, with a confortable safety factor inserted for indeterminancies.

Strain gage evaulation indicated particular coil box loads peak at approximately $2 / 3$ full magnet current and then drop off - a result inconsistent with the original flux plot approach. In addition, unexpectedly high lateral loads appear as bending in the existing vertical stanchion. Because of the structural complexity of the existing stanchion, it was not possible in all cases to deduce unambiguous load criteria from the stress measurements. However, sufficient data were obtained to proceed with certainty on a new design.

Originally it was intended to replace the existing vertical supports with a C-shaped structure to just clear emerging secondary particles. As work continued, it became more obvious that structural strength was not the governing criterion but that deflections must be held to a minimum. Otherwise, coil life could seriously suffer because of increased chafing and working at the clamps. This concept made a C-shaped structure impractical and the overhead-beam-underneath-link support was evolved. It is somewhat appalling to review the quantity of structure required (Figs. 18 and 19) to replace the small centrally loaded median-plane I-beam-steel-plate support originally incorporated, but there was no available alternative.

A somewhat unusual procedure was utilized to avoid the expense and time that would have been required to stress-relieve the two $3800-1 \mathrm{~b}$ overheadbeam weldments and the two lower anchor beams. Although welds were peened during fabrication, undoubtedly many of the joints were at the yield point owing to thermal stresses. To relieve this situation, the two beams were loaded against each other (Figs. 20 and 21) to $150 \%$ of maximum expected service stresses. Thus, plastic flow should occur in critical welds and all service loads thereafter should occur in the elastic region.

The installations were carefully monitored when first put into service. Strain-gage instrumentation on the link supports, together with deflection monitoring at the median-plane gap, indicated that maximum deflections observed were only $70 \%$ of design criteria. How ever, some trouble was experienced with the strain-gage instrumentation and unbelievably high stresses (factor of 5) were apparently being observed. With continued Bevatron operation, the troubles were finally resolved and results from stress monitoring were proven compatible with observed deflection indications. 


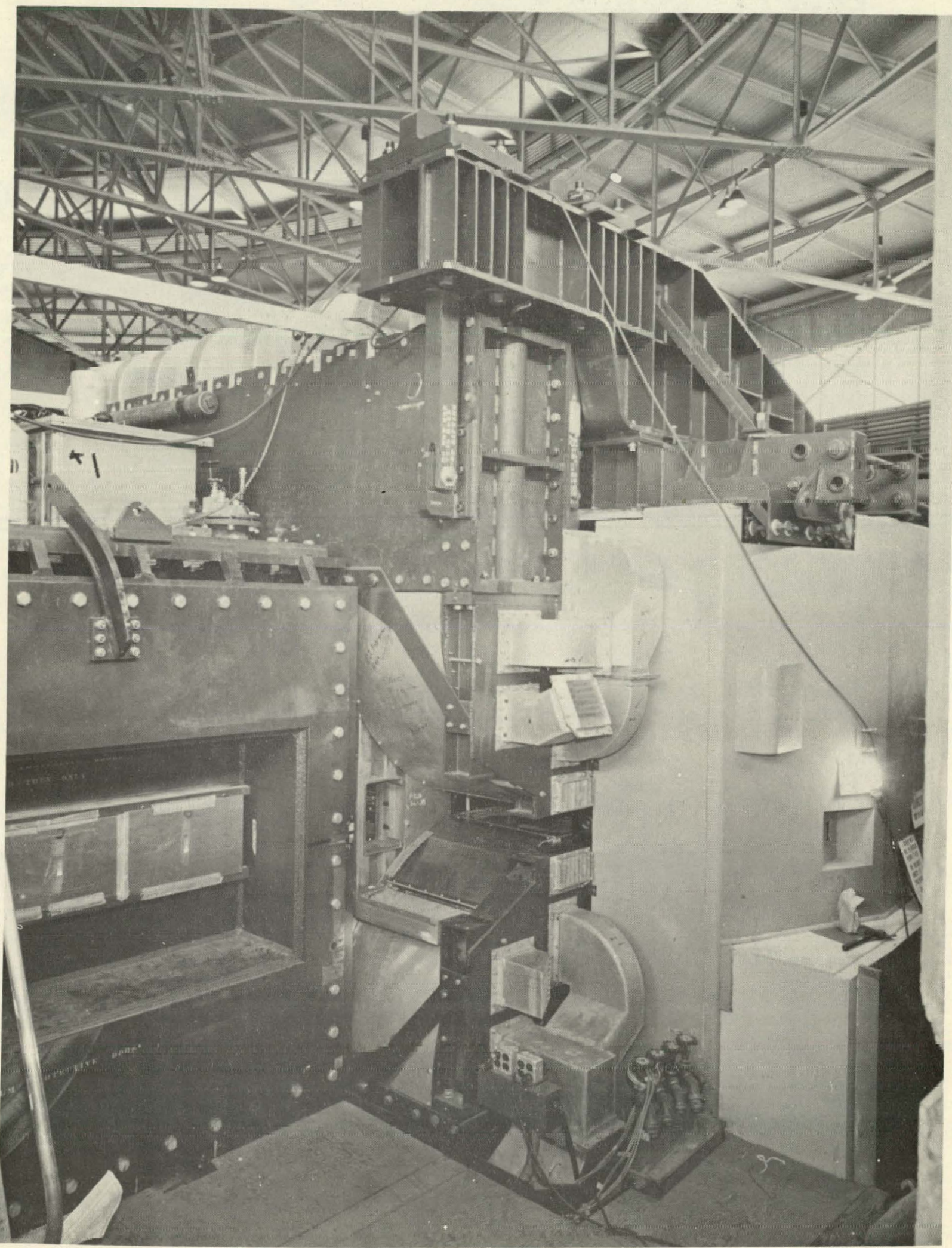

ZN-1915

Fig. 18. Upper coil-box support beam in place at the west

342 experimental area. 


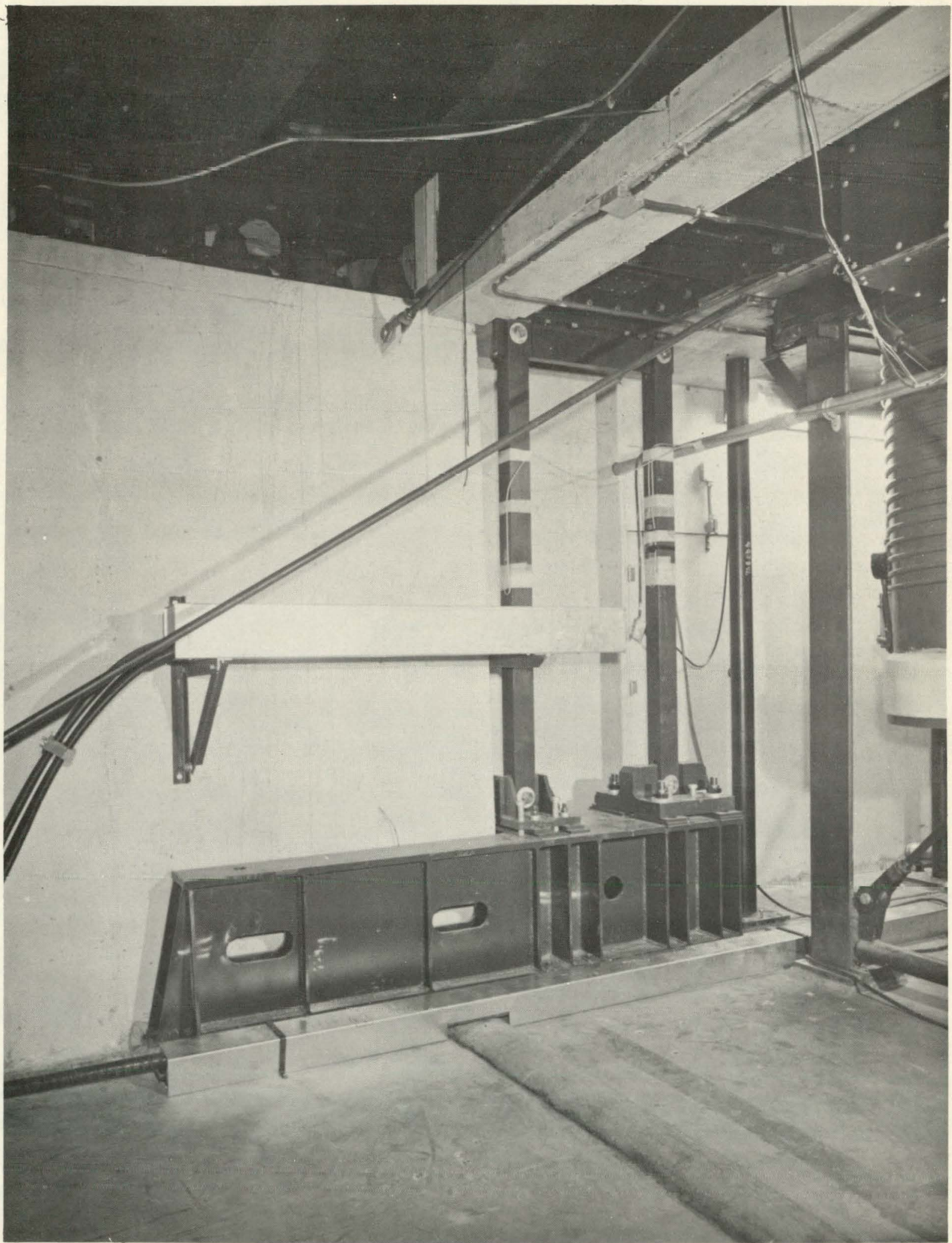

$\mathrm{ZN}-1916$

Fig. 19. Lower coil-box support beam and links in place at the north experimental area. 


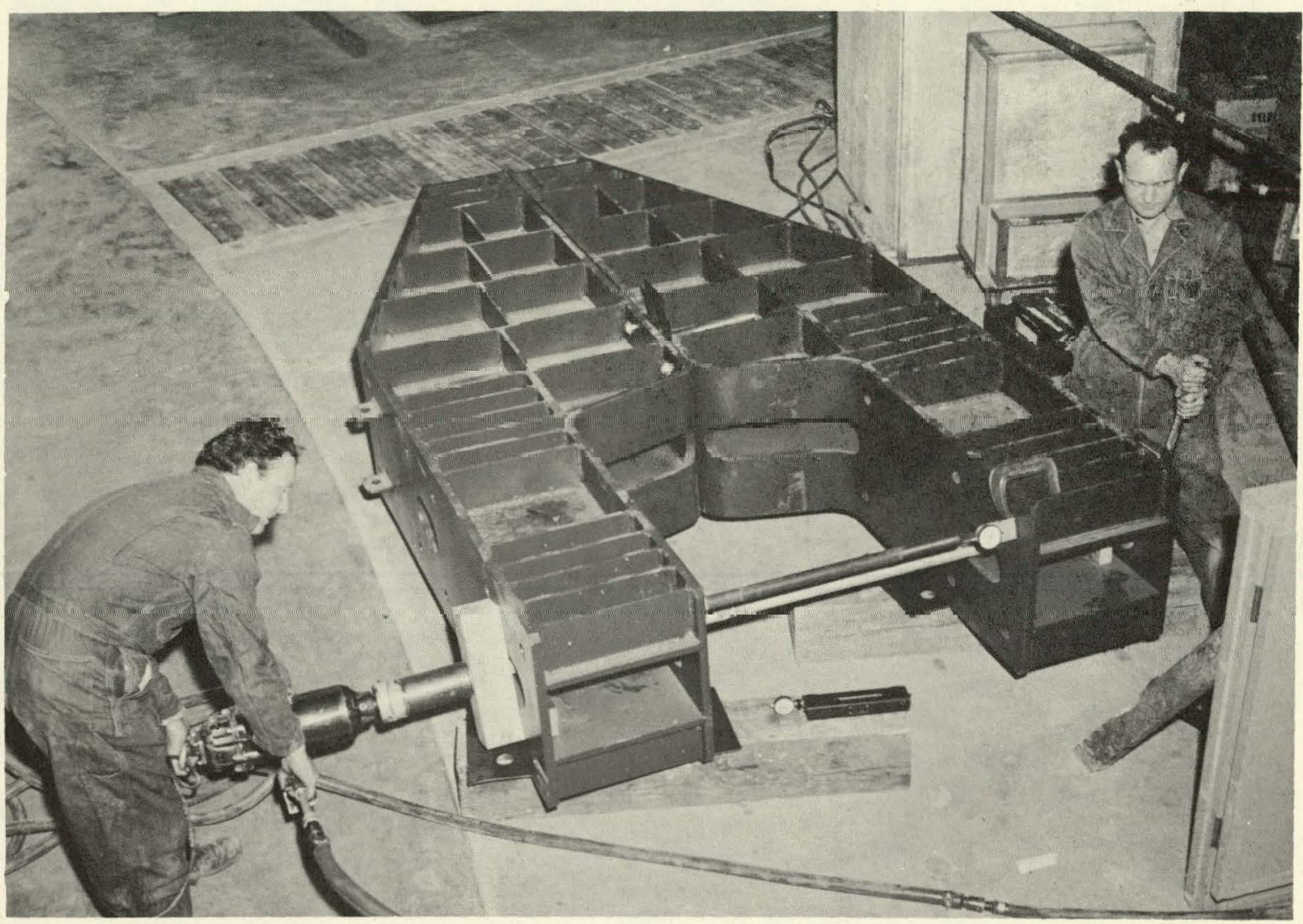

$\mathrm{ZN}-1917$

Fig. 20. Upper coil-box support beams during proof stressing and load test. 


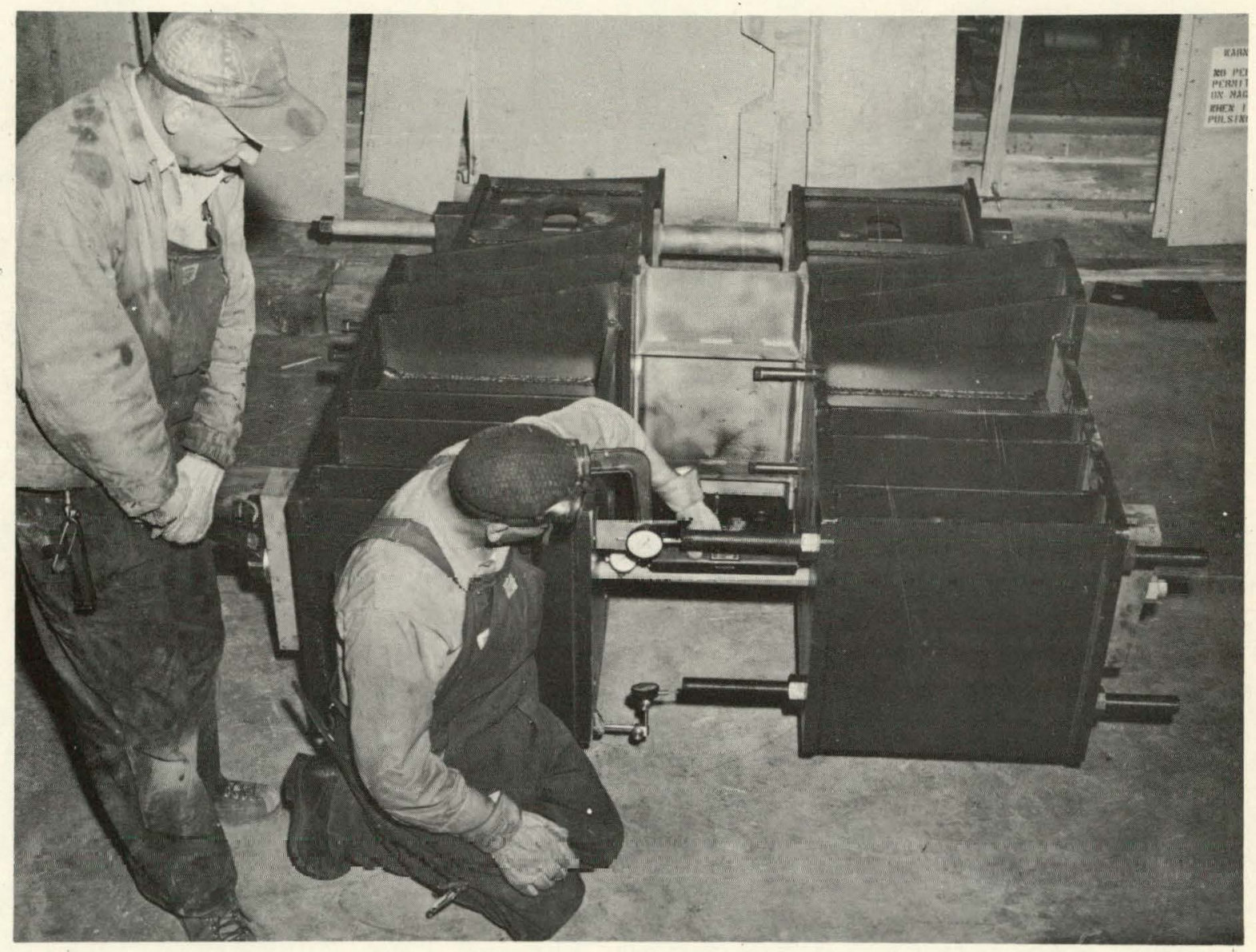

ZN-1918

Fig. 21. Lower coil-box support beams during proof stressing and load test. 


\section{Experimental Facilities}

The experimental facilities that will be available at the conclusion of this shutdown are shown in Fig. 22 (new "north" experimental area, the improved "northwest" and "west" areas, improved radiation shielding, and new target and beam-exit facilities).

\section{Radiation Shielding-Extension of the Shielding-Wall Foundation}

The foundation of the radiation-shielding wall, prior to this shutdown, extended from the north straight section past the west experimental area to the south straight section. The shielding that continued toward the east from both the north and the south straight sections was supported on the original floor slab by placing the wall well away from the magnet foundation, by using timbers to distribute the load, and by limiting the height and thickness of the wall. In the near future, these two extensions will be improved and will be continued east to the linear accelerator from the north, and to the east straight section from the south, and along the linear accelerator to the ion gun (Fig. 23). At the new north experimental area the shielding wall will be made similar to the wall that exists at the west experimental area. To permit these improvements and to allow placing the wall close to the magnet foundation (better shielding and more economical use of the limited building space), suitable footings had to be installed. Figure 24 pictures a section of this recent shielding -wall foundation work during the construction period. The shielding-wall load will be distributed via the reinforced concrete slab to concrete piers, which will carry the load to earth below the foundation level of the Bevatron magnet.

\section{AUXILIARY MOTOR-GENERATOR SETS}

Two additional motor-generator sets are being installed to power auxiliary magnets. One has a 1 -megawatt generator capable of delivering 2700 amperes at 415 volts. The second set is a double-ended unit with two 240 -kilowatt generators: one produces $1225 \mathrm{amp}$ at $195 \mathrm{v}$; the other has an output of $1650 \mathrm{amp}$ at $150 \mathrm{v}$. 
$\omega$

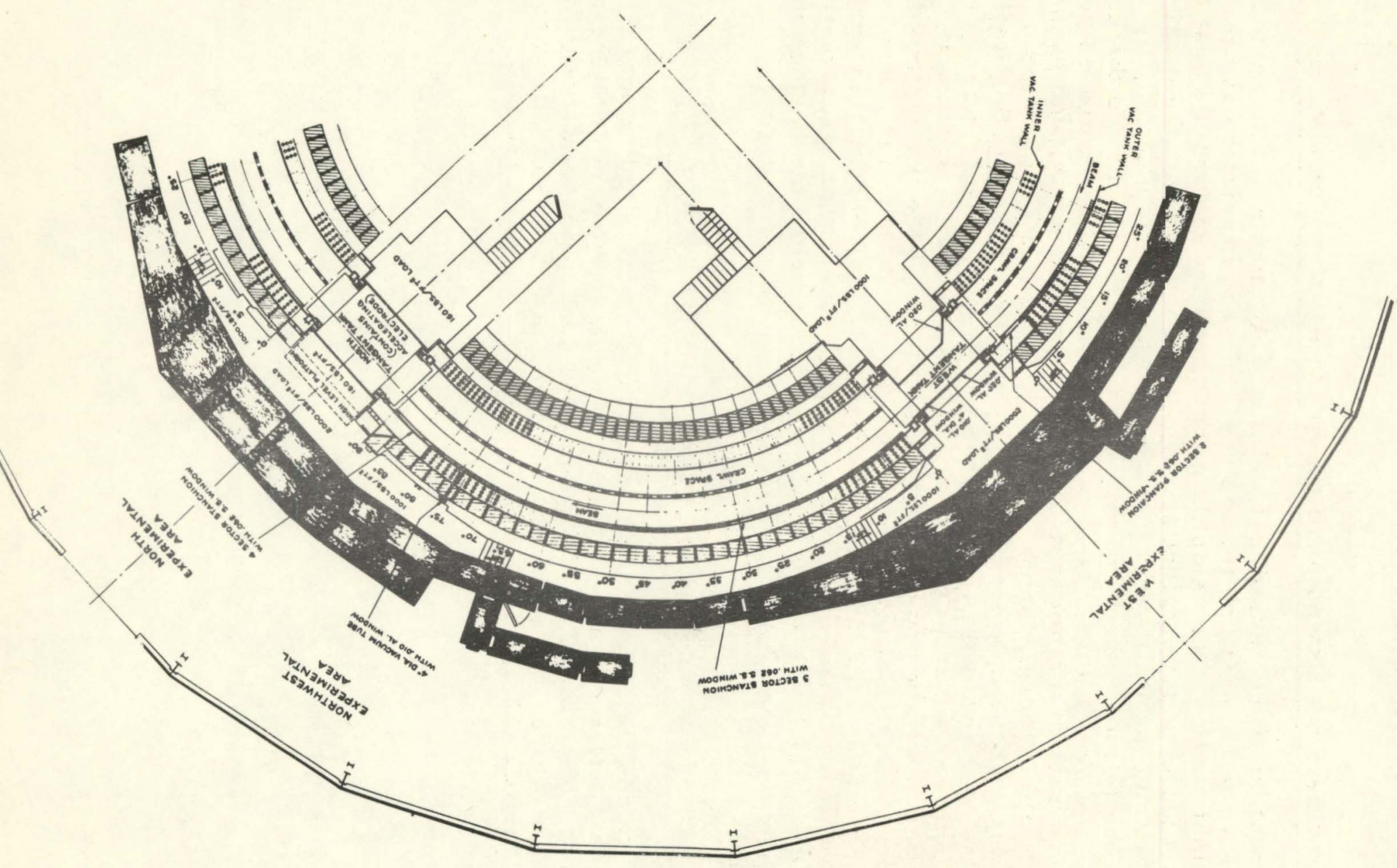

MUB- 170

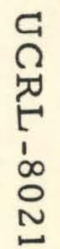

Fig. 22. New experimental facilities. 


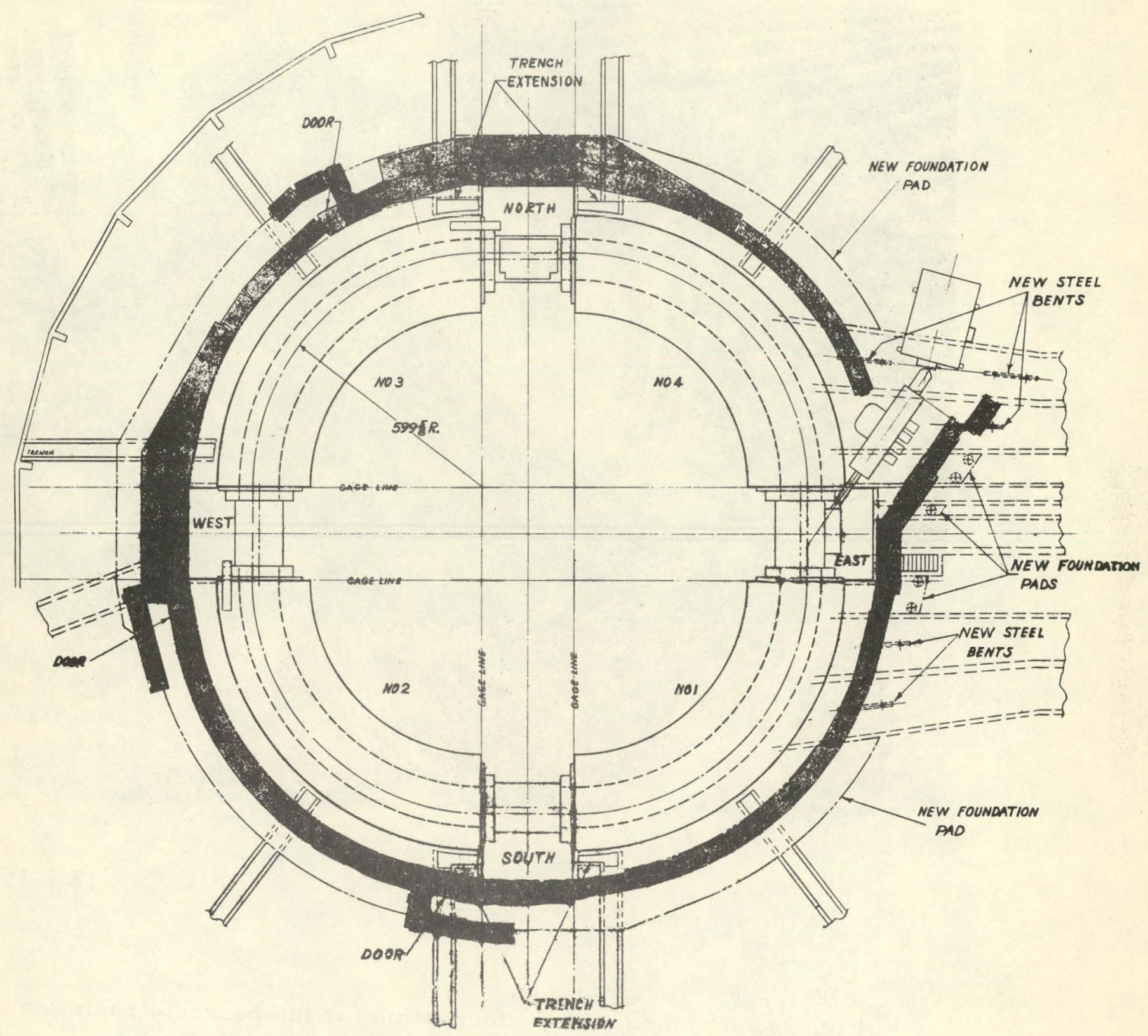

MUB-171 


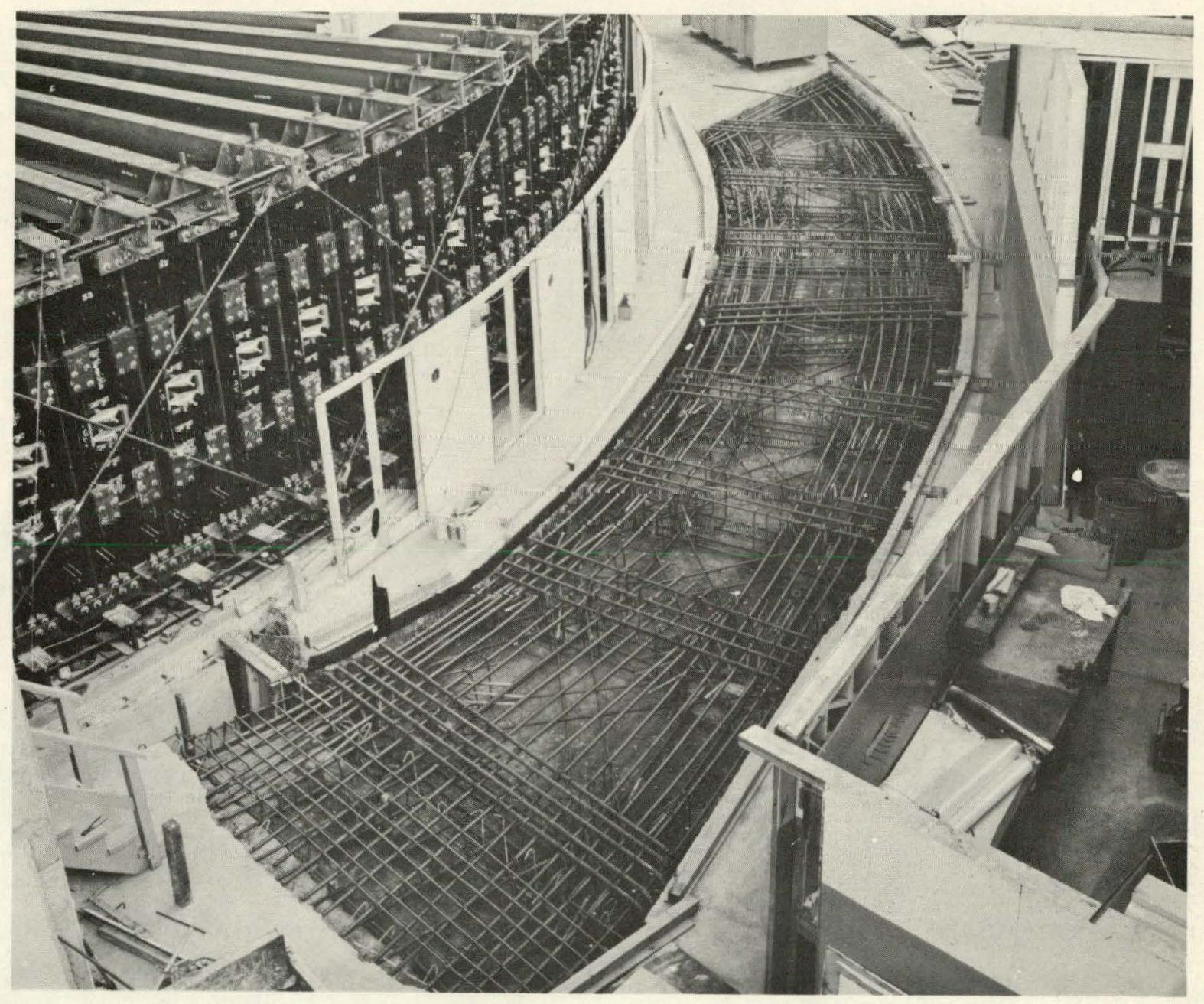

ZN-1919

Fig. 24. Extension of the foundation for the concrete radiationshielding wall, Quadrants I and IV. 


\section{POLE-BASE-WINDING FIELD CORRECTION}

It has been observed that the beam acceptance of the Bevatron can be increased by local perturbation of the magnetic field. ${ }^{3}$ In the past, this has been accomplished by energizing the field-correction windings on the last eleven pole bases at the exit end of Quadrant III. In order to further explore this method of beam-orbit shaping, electrical circuits were installed in such a way that all the pole-base-winding circuits in Quadrant III could be selfenergized and could be individually controlled, sector by sector, from the main control room. The windings of the upper and lower pole bases, in each magnet sector, were wired in series with an appropriate current limiting resistance. Initially, a field correction of about 48 ampere turns per sector will be available. (Each upper and lower pole-base coil consists of 24 turns; the peak-to-peak induced voltage developed in the windings, measured at injection, is $50 \mathrm{v}$; with the upper and lower windings in series, 1 amp of current produces a field correction of 1.7 gauss).

\section{POLE-FACE-WINDING EXCITATION LOOP}

A new pole-face-winding excitation loop consisting of five turns was being installed in the crawl space of the vacuum tank. It is capable of exciting both the pole-face-winding field-correction circuit and the fieldcorrection coil on the new four-sector stanchion. The peak-to-peak voltage induced in this loop, at injection, will be $250 \mathrm{v}$; at full field it will be about $300 \mathrm{v}$.

\section{DEVELOPMENT OF MK VII FLIP-UP TARGET}

Operations during the later part of 1956 made increasing demands on the MK VI flip-target mechanism. A continual pressure existed to increase the operating speed, and a new technique was developed of raising a target, clipping a fraction of the circulating beam, then driving the target down and raising a different target during the same beam pulse. The MK VI mechanism was particularly unsuited to rapid drivedown, since damping was supplied by an eddy-current vane interacting with the Bevatron magnetic field, which developed maximum damping at the up position and almost none at the down position. Several failures in late 1956 emphasized the necessity for re-examining the entire mechanism.

Three particularly weak points needed designing out in any new approach:

(a) standard tube sections for the target-carrier arms allowed sufficient deflection to bind bearings under increased loads from higher speeds.

\footnotetext{
${ }^{3}$ Walter Hartsough, Bevatron Operation and Development XI, UCRL-3614, Dec. 1956.
} 
(b) a different damping method, effective in both directions, was obviously necessary.

(c) more reliable target-position indication must be provided.

Since the target-carrier arms are subject to torsion as well as bending stresses, a box section must be supplied. The correction applied consisted of welding two tapered channel pieces around a center membrane into a box section. Tests indicated that a factor - of -8 increase in stiffness was achieved for a very small increase in weight. Existing MK VI targets use these new arms, as well as the MK VII mechanism.

The double-drive and double-damping problem was solved by rigidly mounting two electrically independent coils at approximately 900 , and using the $m$ alternately as driver and damper. Originally it was thought the braking could be effected by simply short-circuiting the damper coil. Tests indicated that greatly reduced shock loads and hence higher speeds are achieved if the short-circuiting resistance in the damper coil is programmed. Differences in programming are also required for operation at different magnetic field intensities (i.e., different Bevatron ene rgies).

Microswitches were retained as the primary target-position monitor, but a new cam actuation was developed to minimize shock load on the switch. In addition, two units were installed per target so that a spare would be available in the event of service failure of one set. Two other methods of position monitoring were investigated:

(a) a continuous indicating capacitor installed in the coil region, and

(b) voltage monitoring of the damper coil.

Both systems are more difficult to set up and properly interpret, but give more information than the mic roswitch system.

Many additional mechanical simplification were made; one-third of the previously used bearings were eliminated by mounting the coils directly to the drive shaft. Life tests of bearings in vacuum indicated tetrafluoroethylene-impregnated sintered bronze bearings (trade name "Glacier") were far superior to the nylon bearings previously used.

Although the new MK VII mechanical mechanism is simple $r$ and less costly to construct than the MK VI, the power supply is considerably more elaborate. One has exchanged mechanical simplicity and reliability inside the vacuum tank for electrical complications outside the vacuum tank--where it can be serviced. For these reasons, improved MK VI targets will be continued in service and the MK VII units used only where the $75-\mathrm{msec}$ rise speed and fast drivedown are actually required. During test, the mechanism has proven reliable to $10^{6}$ cycles between maintenance periods. A sketch of the new mechanism appears in Fig. 25. 


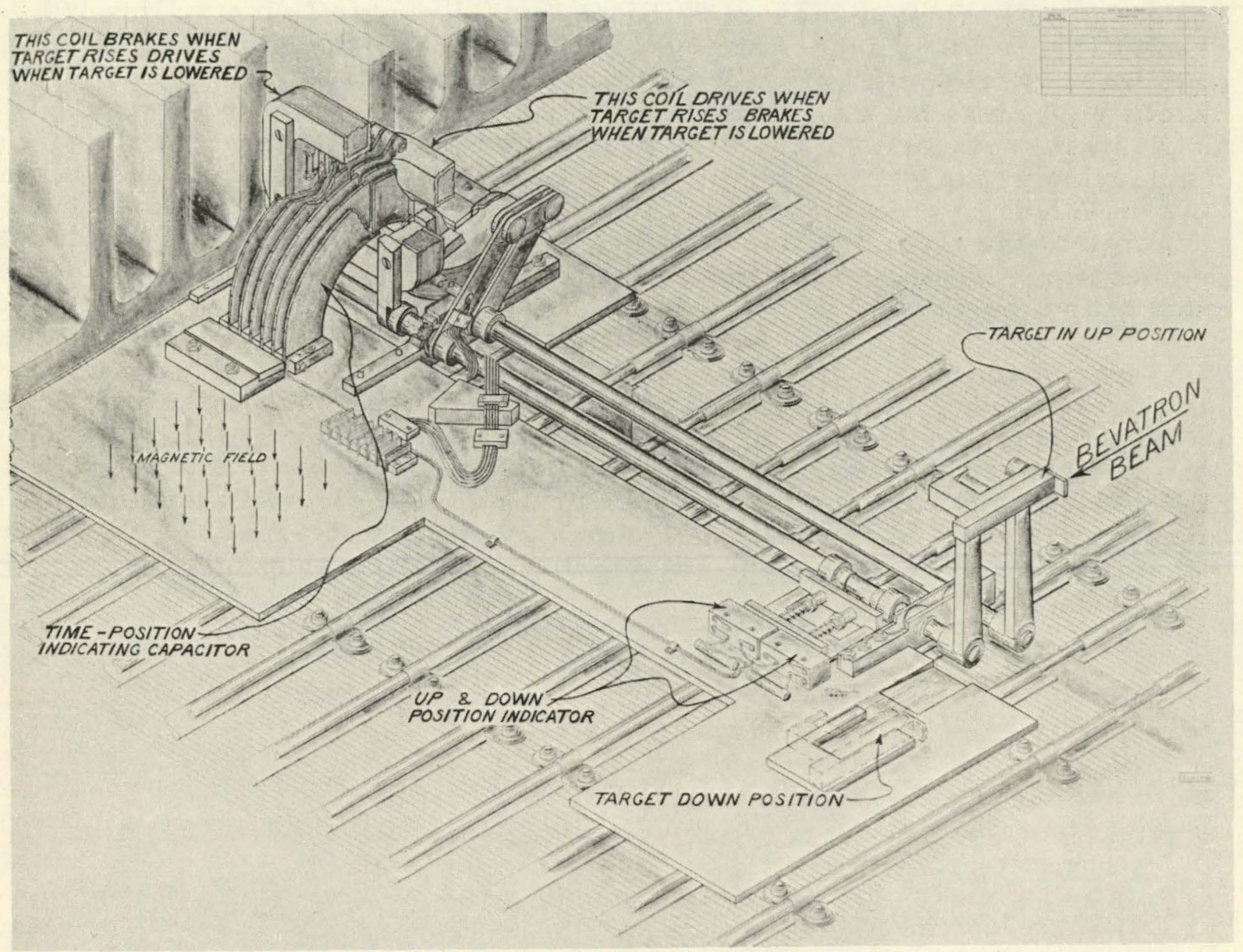

ZN- 1884

Fig. 25. New flip-target mechanism. 


\section{ACKNOWLEDGMENTS}

The Bevatron group leader is Edward J. L ofgren and under him Harry Heard, with Walter Hartsough assisting, is in charge of operations. The Bevatron operators are Robert Anderson, Wendell Olson, and Robert Richter as crew chiefs; G. Stanley Boyle, Gary Burg, Duward Cagle, Norris Cash, Frank Correll, Robert Gisser, William Kendall, Ross Nemetz, Howard Smith, Frank Ulbrich, and Glenn White as crew members. Special development projects were carried out by Bruce Cork, Glen Lambertson, and Emery Zajec. Harold Vogel was the enginee $r$ in charge of the motor-generator sets. The mechanical engineering group was headed by William Salsig; the electrical engineering group was headed by Clarence Harris and Marion Jones. Ivan Lutz directed the electronic development group. Lorenzo C. Eggertz was in charge of the electrical maintenance group. Cedric Larson of Mechnical Engineering coordinated the many phases of the shutdown work and supervised much of the mechanical work.

The successful completion of the coil-rework phase of the shutdown, and the significant progress of the experimental-area phase of the work, are due to the combined efforts of the Mechnical Engineering Department, the Bevatron operating crew, the electronic maintenance crew, the Electrical Engineering Department, and due also to the excellent assistance and coofperation received from the mechanical shops, the trades, the accelerator technician department, and the electronic installation shop. 